\title{
Rethinking postpartum health care
}

\author{
Martha Brady \\ Population Council \\ Beverly Winikoff \\ Population Council
}

Follow this and additional works at: https://knowledgecommons.popcouncil.org/departments_sbsr-rh

Part of the International Public Health Commons, Maternal and Child Health Commons, Obstetrics and Gynecology Commons, Social and Behavioral Sciences Commons, and the Women's Health Commons How does access to this work benefit you? Let us know!

\section{Recommended Citation}

Brady, Martha and Beverly Winikoff. 1993. "Rethinking postpartum health care," Robert H. Ebert Program on Critical Issues in Reproductive Health Publication Series. New York: Population Council. 


\section{RETHINKING POSTPARTUM}

\section{HEALTH CARE}

Proceedings of a seminar

presented under the Population Council's

Robert H. Ebert Program on Critical Issues

in Reproductive Health and Population

December 10-11, 1992

The Population Council

New York, New York

Martha Brady

and

Beverly Winikoff 


\section{ACKNOWLEDGMENTS}

We are grateful to the John D. and Catherine T. MacArthur Foundation for their support of the seminar and this publication.

We would also like to thank Randee Falk for her excellent rapporteur notes that enabled preparation of this document; Alice Tufel for her thoughtful and thorough copyediting; Chris Quigley and Barry Ravitch for their assistance with charts and tables; and Virginia Kallianes for administrative assistance in organizing the seminar and in producing the proceedings.

The Population Council

Robert H. Ebert Program on Critical Issues in Reproductive Health and Population One Dag Hammarskjold Plaza, New York, NY 10017 USA

Copyright $(1993$ by The Population Council 


\section{CONTENTS}

Preface

vii

Introduction $\quad x i$

Chapter 1: The Significance of the Postpartum Period Colette Dehlot, Chair

What is the Cultural Significance Penny Van Esterik 2 of the Postpartum Period?

Postpartum Blues and the Psychological Lucile Newman 5

Significance of the Postpartum Period. Examples from the Field:

Postpartum Service Delivery, Istanbul, Turkey Aysen Bulut 8

Diagnostic Study of Postpartum Services in Tunisia Souad Chater 11

$\begin{array}{lll}\text { Rethinking Postpartum Health Care Judith Bruce } & 14\end{array}$

\section{Chapter 2: Women-Centered Services}

Huda Zurayk, Chair

Two Paradigms of Maternity Health Care

Sally Tom $\quad 20$

Overview of Service Integration:

Anibal Faúndes $\quad 24$

Challenges and Possibilities

Integrating Mother and Child Health

Mohamadou Fall 27

Services in Senegal

Integrating Postpartum Health Care and $\quad$ Soledad Diaz 29

Family Planning: The Chilean Experience

\section{Chapter 3: Responding to Women's Needs: When Do Women Choose} Services?

Kathryn Tolbert, Chair

Overview of the Timing Dilemma

Barbara Mensch $\quad 34$

Client and Provider Perspectives on

Postpartum Contraception

Cynthia Steele Verme 39

Timing and Content of Services: Lessons of the

Honduran Social Security Institute

Rebecka Lundgren

43

Appropriate Technology: A Randomized,

Controlled Trial of the "Kangaroo Mother Method"

in Ecuador

Nancy Sloan 


\section{Chapter 4: Integrating Breastfeeding into Birth-spacing Strategies}

Martha Brady, Chair

Effects of Breastfeeding on Maternal Health

The Role of Breastfeeding in Fertility Regulation Integration of Breastfeeding into Birth-spacing Strategies: The Recife, Brazil Study The Ecuador Experience in Using the Lactational Amenorrhea Method for Birth-spacing
Kathleen Rasmussen 52

Kathleen Kennedy 55

Vilneide Braga Serva 61

Virginia Laukaran

Chapter 5: Contraceptive Methods and Birth-planning Strategies Juan Diaz, Chair

Postpartum IUDs: Challenges and Possibilities
Use of Hormonal Methods in the Postpartum Period

Amy Pollack

69

The Role of Barrier Methods in

the Postpartum Period

Marcia Angle $\quad 72$

Introduction of the Minipill in Mexico

Pat Semeraro $\quad 78$

Doroteo Mendoza,

Aurora Rabago, and

Kathryn Tolbert

Chapter 6: Goals and Opportunities for Postpartum Program Design Beverly Winikoff, Chair

Cost and Cost-Effectiveness Considerations

Ricardo Vernon

in Postpartum Family Planning Programs

Setting a Research Agenda

Anrudh Jain

\section{Afterword: Programmatic Issues at the Seminar on Rethinking Postpartum Health Care Debbie Rogow 92}

\section{Participant List}




\section{PREFACE}

These proceedings provide a summary and synthesis of the papers and discussion from a Population Council invitational seminar entitled, "Rethinking Postpartum Health Care." The seminar was held at Population Council headquarters in New York City on December 10-11, 1992.

The seminar on postpartum reproductive health was the fifth in a series of seminars convened by the Population Council as part of its Robert $\mathrm{H}$. Ebert Program on Critical Issues in Reproductive Health and Population. The Ebert Program focuses on four critical and interrelated topics:

\footnotetext{
* improving and devising new approaches to postpartum care;

* improving the quality of care in family planning and reproductive health services;

* managing unwanted pregnancy and preventing the consequences of unsafe abortion; and

* incorporating attention to sexually transmitted diseases (STDs), including AIDS, into reproductive health care.
}

The Ebert Program grew from an awareness that many important reproductive health problems - and the ways women experience them—have been neglected by policymakers, program planners, and practitioners. Consequently, Council staff work closely with governments, research and health care institutions, scientists, and women's health advocates in developing countries to improve womens' reproductive health care through scientific inquiry, technology assessment, service experimentation, international meetings, and information dissemination.

The purpose of the seminar on postpartum health care was to raise the level of interest in an often neglected period of women's reproductive life, a time with special characteristics and needs, and to broaden the concept of postpartum health care to include issues beyond those of traditional family planning concerns. In addition, the seminar sought to address women's needs for an array of health services during the postpartum period. The meeting focused on a review of the current practices, dilemmas, and possibilities for comprehensive health care services during the postpartum period in order to clarify the elements of good services for postpartum women, and how such services can be designed and evaluated. 


\section{Historical Context of Postpartum Programs}

Postpartum programs are not a new development in family planning. The first organized postpartum program documented in the literature (in 1930) was at the Johns Hopkins Hospital in Baltimore, Maryland. During the next three decades, however, neither international nor domestic family planning efforts were explicitly directed at the recently pregnant woman.

Later, in 1966, the Population Council began a demonstration project aimed at providing family planning services to women after childbirth or abortion. Hailed as a success by family planning professionals, this program has become known as the International Postpartum Program.

The International Postpartum Program was designated a "postpartum" program only because family planning services were located in health care institutions where services were provided for antenatal care, abortion, labor and delivery, and postpartum care, and not because contraception was necessarily initiated at a designated time after childbirth or pregnancy termination.

In the period after 1974, when the International Postpartum Program officially ended, the provision of contraceptive information and supplies immediately after childbirth became an accepted approach to family planning service delivery, reflecting the fact that postpartum programs are widely considered a useful adjunct to standard clinical services. However, by the 1980s, interest in postpartum programs appeared to be waning, evidenced by its virtual disappearance as a topic from the family planning literature.

Recently, policymakers and program managers have expressed enthusiasm for more explicit attention to immediate postpartum services. Still, postpartum programs tend to be viewed in terms of their potential demographic impact rather than as a vehicle to meet the reproductive health care needs of individual women during this period in their lives.

\section{The Seminar}

The Council works in partnership with a large network of scientists, program managers, and health care institutions throughout the developing world. Where possible, efforts are made to provide avenues for dialogue and interchange among colleagues. This seminar was an example of such an exchange. It was attended by more than 70 professionals representing most regions of the world. 
The participants brought to the discussion expertise from medicine, epidemiology, anthropology, nursing, midwifery, neonatology, sociology, demography, and public health, as well as their expertise as policymakers, program planners and managers, researchers, and academicians.

The seminar was organized into six panels, each focusing on a specific area of concern. Each session was a mixture of general discussion about the subject as well as a presentation from field experience. The sessions were centered around the following topics:

1) the cultural and psychosocial significance of the postpartum period;

2) women's preferences for the range of reproductive health care services offered postpartum;

3) appropriate timing of various postpartum services;

4) helping women to integrate breastfeeding into their own strategies for birthspacing;

5) integration of contraceptive technology with women's own strategies for birth planning; and

6) goals and opportunities for program design.

The proceedings of the seminar are divided into six chapters corresponding to the six panels. Each chapter includes presentation summaries, which retain the informal tone of the talks while clearly communicating the ideas that were expressed.

These proceedings were compiled not only to record the events of a single meeting, but also as a way to share the insights gained throughout the seminar. It is hoped that the dissemination of these proceedings will allow those who did not attend the seminar to benefit from the ideas and lessons exchanged there. Moreover, it is our hope that the results of this meeting will stimulate thinking about new approaches to postpartum reproductive health care.

The presentations inspired an active exchange of information and ideas, and lively discussion followed each of the panels. Overall, the group agreed on a large number of issues, while other topics may require further discussion.

The seminar participants agreed on the following:

* Postpartum health care can most effectively meet the needs of women if conceptualized broadly, not simply in terms of family planning concerns. 
* Programs will be most acceptable and effective if their design accounts for the plurality of clients and the diversity of needs during this period.

* It is important to direct particular attention to the timing and content of information and counseling provided to postpartum women. Labor and delivery are not appropriate times for counseling and provision of family planning services.

* Hormonal methods are not the method of first choice for lactating women, and their use prior to six weeks postpartum is not recommended.

* It is appropriate to offer sterilization services to women at a time that is convenient for them-that is, immediately postpartum - only if the service is explained to them ahead of time and they make their choice during the pregnancy.

Areas for discussion and further study include the importance of testing different service delivery models that integrate mother and infant health-care services, issues related to sexuality and sexual behavior, and the cost of postpartum family planning services from a quality-of-care perspective.

- Martha Brady

- Beverly Winikoff 


\section{INTRODUCTION \\ What is Postpartum Reproductive Health Care? \\ based on opening remarks by Beverly Winikoff}

Despite its Latin origin suggesting scientific precision, the term "postpartum" has no specific definition with regard to the health care of mothers and babies immediately following childbirth. In fact, the time period to which "postpartum" refers is generally unclear.

In the case of postpartum health care, our casual use of language has caused problems. The word "postpartum" itself has a meaning so inexact that our communications with each other are sometimes flawed when we speak of it.

As an example, notice the difference between the words prenatal and postpartum. Clearly, pre refers to "before" and post means "after," but the referent event is named very differently in the two words. Natal is a baby reference, and partum is a mother reference. Yet, we hardly ever use the word "prepartum" in talking about health services for mothers before babies are born, and we hardly ever use the word "postnatal" with respect to services given to mothers after babies are born. Is this a subtle indication that the services before birth are aimed at the health of the baby and the services after birth are for the well-being of the mother?

I have tried to think of phrases we commonly use that incorporate the word "postpartum" to understand how we think of this word and its meaning in our speech. In fact, "postpartum" is not often used in common parlance, but three uses come to mind:

\section{○" postpartum check-up,}

\section{- postpartum blues,} and, of course,

\section{$\circ$ " postpartum family planning program.}

All of these uses suggest that "postpartum" has something to do with a time period that occurs quite soon after having a baby. In other words, it has a time dimension, but, surprisingly, it lacks specificity. In fact, the word "postpartum" has no clear meaning, 
especially as used in the words postpartum family planning program, and this lack of a clear meaning has caused a fair amount of confusion. Think of the question, "Are you in favor of or opposed to postpartum family planning?" The question makes little sense to anyone who is committed to seeing that women have the ability to regulate their fertility using safe and effective methods.

In fact, I looked at the word "postpartum," and its use in programmatic terms and have found that it is used in many different ways.

I recently read a description of the concept of "postpartum programs" as offering information and services at the "prenatal visit," at the time of delivery, and at a six-week check-up. If we are using exact language here, can a postpartum program be defined as having a prenatal component? Why would we call a service a "postpartum" program if, to be an appropriate and complete service, it needs to offer care before a birth as well as after it? Why even call it a family planning program, in fact? Why not simply view family planning as a component of appropriate care for pregnant women, newly delivered women, and other women who come for reproductive health services?

Does the perceived need to develop something with the special name of a "postpartum program" present us with difficulties because it derives from a point of view that starts with contraceptive technology and not with people, with methods and not with women? In fact, all thoughtful writings have acknowledged that women can receive and would prefer family planning services at any number of points in time, and the services ought to be available at all of those times. So what is the special nature of a "postpartum program"? To some it may mean the availability of family planning services to women who have recently had a baby, but to others it has a defined meaning as a type of service promoted independently, in addition to what is usually called "maternal health care."

The point, of course, is that there is no place to turn for an explicit definition of "postpartum family planning programs"-nor, certainly, do we have pretensions of undertaking such an effort at this seminar. Instead, we are trying to understand what has been meant by postpartum family planning programs, to begin to understand whether they meet women's needs and how they can be evaluated. In fact, our explicit goal is to venture beyond a concept of the "postpartum period" as merely a fine time to begin using contraceptives, and to find out more about its true meaning in women's lives. By doing that, we hope to develop information and perspectives that will inform the design of truly useful health services for the period after a baby's birth.

Family Health International summarized its 1990 deliberations on this issue and 
suggested that two important characteristics of successful postpartum contraception programs are:

1) offering of a variety of contraceptive options, and

2) integrating contraceptive services with services that promote or protect maternal and child health generally.

Nonetheless, the same document observed that most postpartum programs have some or all of the following flaws:

1) limited integration with any other maternal or child health-care programs,

2) medical orientation with an inability to consider individual needs, and

3) a focus on the immediate delivery of one contraceptive method, with poor followup.

It should not surprise us that narrowly focused programs miss important opportunities to respond to women's needs. Maybe we should appropriate Freud's famous question and ask, "What do women want?" The question is pertinent to the range of services offered, their content, and their timing. Certainly, we need to realize that even programs are not integrated-women are integrated. A woman is only one person, but she has to respond in an integrated way to the multiple demands of her body, her new child, her sexual relationship, and her partner; to her obligations as provider and nurturer in a family, and perhaps to other economic, social, and ceremonial obligations.

If, as providers, policymakers, and managers we choose to respond to only one of the needs of consumers, we should not be surprised if some of them view our offering as irrelevant or of low priority. Part of our problem, perhaps, comes not from being ill-intentioned but simply from being ill-informed. We have done very little to clarify or illuminate women's perceptions of services in the postpartum period, women's specific needs and desires, their hierarchy of values, and the best response to their ability to use services. Indeed, acceptability research is often done with respect to technology but not terribly often with respect to services. In part, that is because the latter task is much more complex. We still need to know what services are acceptable, desirable, and preferable, but it is harder to use most of the endpoints that have been suggested so far as appropriate ways to measure the acceptability of specific technologies. 
It is much more difficult to measure acceptability when dealing with complex service delivery structures, and it is even more daunting to imagine types of services that have not yet been developed or tried. But we still need to know how services are perceived by users, providers, program managers, and policymakers if we want to be able to offer a broad-based, full integrated constellation of services that encompasses the "big picture" with regard to family planning and women's health. Only then can we provide a "total" reproductive health program that includes the kind of overall postpartum services that women truly want and need. 


\section{CHAPTER 1: \\ THE SIGNIFICANCE OF THE POSTPARTUM PERIOD \\ Colette Dehlot, Chair}

\section{What Is the Cultural Significance of the Postpartum Period? \\ based on a presentation by Penny Van Esterik}

In order to examine the cultural significance of the postpartum period, we need to look first at the concept of "culture." The need to discuss culture is especially great because as the concept is increasingly used in health research, confusion about various definitions becomes evident. Culture is sometimes defined broadly to mean the totality of the different domains of life (religion, subsistence activities, etc.) and their interconnections. It is sometimes defined narrowly to refer to folk beliefs, values, attitudes, and, in the health context, health ideologies.

Either of these definitions of culture poses potential dangers. The broad definition can often produce stereotypes, based on static categorical features drawn out of context. The narrow definition can result in a view of culture as an obstacle to be overcome-for example, by health professionals who want to help patients. The underlying danger in both cases is a reification of the concept of culture - culture is seen as a "thing" and, more specifically, as a thing possessed by "others." We tend to forget that we, too, have our cultural baggage and that Western health professionals share a biomedical culture, rooted in Western traditions, that shapes their values and actions.

Health professionals' views of the postpartum period, then, are shaped by their culture. For that reason, if we are to develop "culturally sensitive" postpartum care, we will need to, despite the difficulties of self-reflection, look closely at our own culture and at the biomedical model of the postpartum period. What follows is a comparison between approaches to the postpartum period in the Western biomedical model and in non-Western, nonindustrial societies. The intent is not to glorify non-Western approaches, but to discover whether they can help us rethink the Western biomedical model and to identify the factors that might underlie cross-cultural differences in approaches to the postpartum period.

\section{The Western Biomedical Approach versus Traditional Approaches}

In the Western biomedical approach, the postpartum period is seen as a time period of uncertain duration-essentially from the delivery of the placenta to the six-week check-up- 
with little connection to previous or subsequent events and care. Postpartum depression and postpartum blues are often mentioned. The period is standardized, with little if any distinction made between first and subsequent births. Sexual abstinence until the six-week check-up is often recommended. There is a shift in "elite" health practitioners from the obstetrician to the pediatrician, with maternal care provided by "non-elite" personnel such as public health nurses. Compared with the prenatal period, there is relatively little emphasis on the woman's health. Potential stresses on the mother are largely ignored, and there is no community involvement or support.

Ethnographic studies of various non-Western societies reveal patterns remarkably different from those described above in all areas but sexual abstinence. Postpartum is seen not as a discrete period but as part of a time that begins when a woman first knows she is pregnant and extends to the end of breastfeeding (sevrage). Postpartum depression and blues either are not emphasized or do not occur. The first birth is treated as different from the others, as crucially important for establishing a good pattern. Although there is often little emphasis on prenatal care, there is continuity of care, with, for example, a midwife treating the mother and baby as a dyad.

Above all, the postpartum period is seen as a vulnerable time for the mother in nonWestern societies. In many religions and societies, the 40 days following the birth are a ritually marked period associated with sexual abstinence. The emphasis is on care of the mother, which might include massages, bathing, and food prescriptions and proscriptions. (Prescriptions are associated more with societies where women have a relatively high status; proscriptions occur in societies in which their status is lower.) The woman is relieved of her ordinary tasks, which are assumed by female kin. Community involvement and support are extensive. Most of all, the postpartum period is a time for restoring the new mother to the life of the community.

\section{An underlying difference}

Perhaps at the heart of the differences between Western and non-Western approaches to the postpartum period are different concepts of time. Western concepts of time tend to be linear and compartmentalized, while non-Western concepts tend to be cyclical and less compartmentalized. These different tendencies might help explain some of the differences noted above. Moreover, there are many kinds of time, including self time (the individual's own experience of past and present), interaction time (time expressed in relations with others), and institutional time (the daily, weekly, and yearly cycles in a society). Related 
to institutional time is the issue of periodicity. Women's lives, and not only in non-Western societies, tend to be highly constrained by periodicity-by the need to perform many tasks that are repeated, frequent, and non-postponable. High-periodicity tasks are considered of low value and are usually assigned to low-ranking persons. Non-Western approaches to the postpartum period essentially help women to remove themselves from institutional time and from the usual constraints of periodicity, and to focus instead on interaction time with the infant.

\section{Conclusion}

Non-Western approaches to the postpartum period are threatened by current conditions of rapid change. Urban migration, cash cropping, and other such changes, along with women's growing involvement in Western institutions in areas including health care, have increased the importance of institutional time and have replaced community supports with a reliance on the conjugal relationship - a relationship frequently characterized by an imbalance of power, with the husband claiming economic and sexual rights. As a result, women in the postpartum period often face the worst of both worlds.

If non-Western approaches to the postpartum period disappear, we lose alternative solutions to a human problem and thus some of the diversity so critical to humanity. It is important that we not impose a single, Western solution as a replacement for a variety of non-Western solutions. Keeping those other solutions in our cultural repertoire provides us with other models for thinking about postpartum care. As the preceding discussion also makes clear, in planning postpartum services, we need to pay particular attention to the status of women, their social supports, and the systems of time and power within which they operate.

\section{Postpartum Blues and the Psychological Significance of the Postpartum Period} based on a presentation by Lucile F. Newman

Postpartum blues is a mild depressive condition beginning about the third day after childbirth. Common complaints include insomnia, restlessness, fatigue, irritability, sadness, headaches, and lability of mood. Studies indicate that in the United States between 50 and 70 percent of women who give birth experience postpartum blues. The condition is selflimiting and needs to be distinguished from postpartum depression, a true depressive state 
affecting a small number of women (one to two per 1,000), most of whom have previously experienced depression.

The pervasiveness of postpartum blues may not be surprising when we consider the huge psychosocial changes brought about by childbirth. These changes include-in addition to delight at the new baby and exhilaration-sleep deprivation, relationship intrusion (personal, sexual, and psychological), anxiety about parenting skills, seemingly permanent lifestyle changes, and an increased need for social support.

A further contributing factor might be the conflicts inherent in a medicalized system of childbearing. Normal reproductive phenomena such as pregnancy are labeled abnormal; aggressive interventions such as induction of labor and caesarean section, along with new and powerful medical technologies, transform a personal experience into a scientific event and shift the locus of control from the woman to the physician. As a result, the experience of childbirth might conflict with an expectation of autonomy, and this conflict could contribute to depressive feelings in the postpartum period.

A review of the literature reveals widely ranging explanations of postpartum blues, with each discipline finding the factors it examines to be causative. Thus, endocrinologists locate their explanation in hormonal changes, family therapists in interpersonal family tensions, and anthropologists in cultural factors.

\section{Hormonal Changes as a Possible Cause for Postpartum Blues}

Pregnancy and childbirth are, of course, associated with significant and varied physiological changes. During pregnancy there are high levels of estrogen, progesterone, and cortisol, and these levels drop at parturition. Labor and delivery result in generalized physiological stress; there can be dehydration, blood loss, and perhaps sepsis. The question, though, is whether specific changes in body chemistry and physiology occur that might produce postpartum blues. Several such changes have been hypothesized. Postpartum blues has been attributed to:

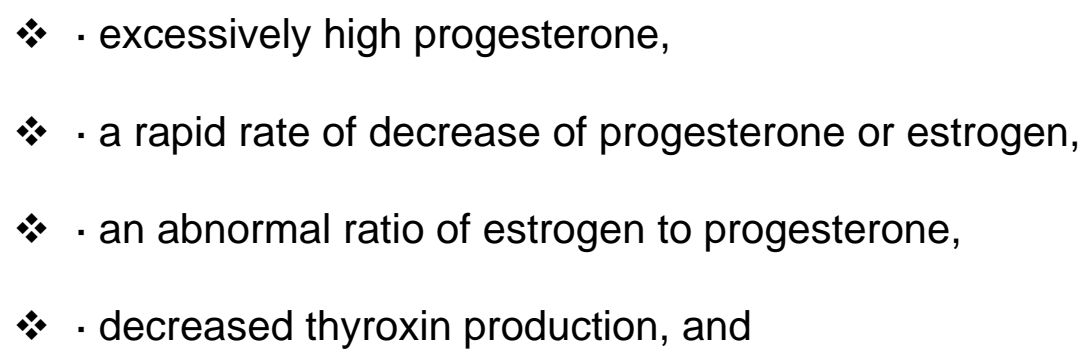




\section{* an abnormal tryptophan and cortisol concentration.}

While these hypotheses are interesting, so far none has been strongly supported. For example, although reports of psychosis upon withdrawal of large amounts of oral contraceptives might point to a role for rapid decrease of progesterone or estrogen in postpartum blues, when women in these studies underwent progesterone treatment the results were not consistent and the treatment was not largely effective. Similarly, recent studies on thyroxin levels in the postpartum period seem to contradict earlier studies that showed decreased postpartum thyroxin production (D'Addato, et al., 1991; Hannah, et al., 1992; Lanczik, et al., 1992; O'Hara, et al., 1991).

In short, while clearly overwhelming hormonal changes follow childbirth, which need to be taken into account, their specific role in postpartum blues remains to be established.

\section{Evidence from the Cross-cultural Literature}

Cross-cultural work on postpartum blues points to significant differences between the postpartum period in Western and non-Western societies. For example, Stern and Kruckman (1983) found that in non-Western societies the postpartum period was frequently structured by elements including cultural recognition of a postpartum period, measures to protect the new mother, social seclusion, mandated rest, assistance with tasks, and social recognitionthrough rituals and gifts—of the mother's new status. Harkness (1987), taking off from suggestions in Stern and Kruckman, found that cross-cultural evidence, including her own work with the Kipsigis of Kenya, indicated a strong role for culture. Among the Kipsigis, for example, women did not experience postpartum blues. Harkness concluded that three common explanations for postpartum blues-the biological model focusing on hormonal changes, the psychological model focusing on women's characteristics, and the stress model focusing on the stress of childbirth - could not suffice. Culture had to be seen as "a powerful mediating factor between the physiological processes related to childbirth and their psychological outcomes."

In general, the cross-cultural literature on the postpartum period has noted a lack of psychological interruption, with the main change being a sense of euphoria. It is possible, although by no means established, that there is a connection between this lack of psychological interruption and the existence of social supports and, correspondingly, between postpartum blues and the lack, for many Western women, of such supports. In any case, it appears clear that the factors behind postpartum blues are highly complex and interrelated. 


\section{Postpartum Service Delivery, Istanbul, Turkey \\ based on a presentation by Aysen Bulut}

The Institute of Child Health, in Istanbul, Turkey, is conducting a diagnostic study of postpartum family planning service delivery in Istanbul, with particular emphasis on the extent to which it meets women's needs and desires. The potential importance of strengthening postpartum family planning programs is suggested by the fact that short birth-spacing is the greatest contributor to excessive fertility, as well as by a lack of linkage between hospital maternity and family planning services. Although the study is still in progress, some preliminary results are available.

\section{Objectives and Methodology}

Within the broad goal of analyzing postpartum service delivery, the study has several specific objectives:

1. Develop and test a research methodology for defining women's perspectives on postpartum family planning.

2. Identify women's needs and desires with regard to family planning and other healthcare services in the postpartum period.

3. Determine local postpartum beliefs and practices.

4. Identify existing postpartum family planning services in the study area.

5. Identify personnel and other resources potentially available for postpartum family planning service delivery.

The initial phase of the study was an assessment of existing services. Data were obtained from two hospitals, one health center, and two maternal-child health centers through informal interviews with administrators and providers, examination of records, direct observation of service delivery, and structured interviews with providers.

The second and third phases centered on identifying women's postpartum beliefs and practices, as well as their needs and desires. In the second phase, focus group discussions were held with women one to two months after hospital delivery (two groups of 13 women), five to six months after hospital delivery (two groups of 10 women), and one to six months 
after home delivery (three groups of 18 women). Information obtained from these discussions was used in developing questionnaires, which were used for the structured interviews of the third phase. The interviews were conducted with 184 women who had delivered in hospitals; they were conducted at one to two months postpartum and, for 84 percent of the women, at five to six months, as well.

\section{Findings: Postpartum Beliefs, Practices, and Needs}

In view of the great similarities between the findings from the focus group discussions and the one-two-month interviews (the five-six-month interview results are not yet available), the two sets of findings are discussed together here; the percentages that are given refer to the interview data.

The vast majority of the women (88 percent) had received prenatal care, but in most cases family planning counseling was not included. Whether they delivered at home or in the hospital, women often were not given much information by providers; when postpartum counseling was given, it rarely (for 2 percent of the women) included information on family planning. Most women were highly interested in limiting and spacing births; in fact, in some focus groups the ideal interval between births was seen as three to six years.

The women had a very definite sense of a 40-day postpartum period. They saw it as a period for resting and taking good care of oneself. The vast majority of women stayed home for the entire time, and most received help from female relatives.

Breastfeeding was considered superior to bottle feeding and was widely practiced (92 percent), but exclusive breastfeeding was rare; 88 percent of the women in the one-twomonth interviews had already introduced supplements.

There was a lack of consensus on the timing of return to fertility and on the effectiveness of breastfeeding as protection against pregnancy. In the focus groups, most women said they abstained from sex during the 40-day postpartum period, for reasons of religion and health. However, in the interviews a majority (61 percent) said they had intercourse at least a few times within six weeks of the birth. The time at which they planned to initiate contraception varied; about half of the women planned to begin six to eight weeks postpartum.

When asked about their needs and desires for postpartum counseling and for family planning in general, the women gave a range of answers. They wanted information on the advantages and disadvantages of different contraceptive methods, on how and when to use them, and on the risks involved. However, whereas a majority of women thought the 
information should be provided during prenatal visits, some preferred the time between delivery and discharge from the hospital, and yet others saw the end of the 40-day period as the ideal time for the provision of this information. Moreover, many considered information on baby care a more important aspect of postpartum counseling than family planning. Women also expressed the view that postpartum counseling was most important for first-time mothers.

\section{Conclusions}

In the study area, the risk of pregnancy during the postpartum period might be high, as very few women practice exclusive breastfeeding and sexual abstinence is not common. Yet women are well aware of their needs for family planning even if they emphasize baby care as their first priority in the immediate postpartum period. Current family planning programs are not well suited to meet women's postpartum needs. Many service providers do not generally consider family planning counseling as part of their medical tasks. Moreover, many had narrow views about when family planning information should be given (i.e., just after delivery, not prenatally) and to whom it should be given (i.e., mainly to those in high-risk groups such as older women or high-parity women). Finally, as noted earlier, many women who want information do not receive it.

\section{Diagnostic Study of Postpartum Services in Tunisia}

based on a presentation by Souad Chater

A preliminary study was undertaken in Tunisia to assess postpartum family planning services in general and the role of breastfeeding in particular. The intention was to determine whether further study of ways to improve service delivery are currently feasible. In order to look at a variety of institutions and women, data were collected from three medical facilities in Tunis and two facilities in the rural area of Medjez El Bab.

\section{Methodology}

In Tunis, data were collected from the University Maternity Center (the largest maternity hospital in Tunisia), a maternal and child-health ( $\mathrm{MCH}$ ) center, and a dispensary. The two facilities in Medjez El Bab were a regional hospital and an $\mathrm{MCH}$ center. Information was obtained through direct observation of the medical facilities and their personnel, and through medical records related to postpartum services, through in-depth interviews and 
focus group discussions with personnel and clients. Personnel in the interviews and/or focus groups included physicians, sages-femmes (nurse-midwives), and social workers. The clients were women who had delivered at a medical facility, were in their sixth to ninth month postpartum, and were not first-time mothers. The focus group discussions were intended to provide information on women's knowledge of breastfeeding from both nutritional and contraceptive standpoints, on their sexual and contraceptive practices postpartum, and on desired and available postpartum services. The following are some findings from the focus group discussions. As the data are now being analyzed, these findings should be regarded as preliminary.

\section{Postpartum Beliefs, Practices, and Needs}

Following delivery, the women stayed in the medical facility for between one and seven days, depending on their health and the health of the baby. Mothers and babies were kept together. Mothers were counseled on the importance of breastfeeding from the outset and were advised to have a postpartum check-up, including a family planning consultation, on the fortieth day after delivery.

Women perceived the 40-day postpartum period as a time for resting, recuperating, being taken care of, and adapting to a new life. They stressed the importance of hygiene and rich foods during this period and said that other women in the family had taken care of them and helped with their newborn.

Breastfeeding was seen as important for the mother and child, and breast milk was seen as nutritionally superior to bottle milk. Almost all women in the focus groups had breastfed their previous baby for 1 to 15 months. However, for many women exclusive breastfeeding lasted only a few months. Supplements had been introduced because the women went back to work, because they had been advised to introduce supplements, and in some cases, because they thought that continuing exclusive breastfeeding would adversely affect their health.

Women resumed sexual relations 8-50 days after the delivery. Traditionally, sexual relations are resumed after the fortieth day, when the postpartum period is considered to be at an end and women go to the bath to be purified. Most women did, in fact, wait until after the fortieth day; the reasons they gave for doing so varied. Traditional, rural women tended to feel it would be sinful to resume relations before that time. Middle-class, urban women spoke more of health and hygiene and of the 40-day postpartum period as a time for adapting to and focusing on the baby. Women also spoke of knowing someone who had resumed 
relations prior to the fortieth day and incurred some sort of misfortune. Focus group discussions with sages-femmes confirmed that, traditionally, earlier resumption of sexual relations was considered a sin, but that this view was now changing.

There was consensus among the women that once they resumed sexual relations they risked pregnancy unless they adopted a contraceptive method. The women had not been counseled on the effect of breastfeeding on fertility; some women were familiar with the idea, but none was convinced of its effectiveness.

As already noted, before leaving the medical facility where they had delivered, women were advised to go for a 40-day postpartum check-up, which would include family planning counseling. Many women, however, actually didn't go until later, when they had a health problem or decided to use a contraceptive method.

A few of the women had never adopted a reliable method of contraception such as the pill or IUD. Even some who used modern methods evidently had difficulty avoiding unwanted pregnancies, often because they lacked knowledge about contraception generally and/or about the specific method they used. Moreover, in many cases nurse-midwives won't recommend the pill after delivery, as they say it affects the ability to breastfeed. Women are not necessarily instructed in how they can use breastfeeding as part of a birth-spacing strategy, even though figures from the Demographic and Health Survey of 1988 indicate that, for women in Tunisia, breastfeeding on average lasts 15.5 months and postpartum amenorrhea lasts 7.2 months, suggesting that breastfeeding could be used effectively in this context.

\section{Conclusion}

Although the availability of postpartum family planning services benefits many women by enabling them to adopt a contraceptive method at a particular point, it does not provide them with the means of adopting a comprehensive family planning strategy based on a range of methods, including breastfeeding.

The preconditions for a study of ways to improve postpartum services in general and to increase awareness of the effects of breastfeeding on fertility in particular do exist in Tunisia: There are adequate medical facilities, competent and sufficient medical and other personnel, and an awareness of the need for change.

The postpartum period is viewed as a significant time in women's lives and one that provides an important foundation for the provision of family planning and other reproductive health services. 


\section{Rethinking Postpartum Health Care}

based on a presentation by Judith Bruce

Postpartum programs tend to be too narrow in their content and goals, in part because they proceed from assumptions about women's lives and reproductive experiences that are incomplete or incorrect. To better align postpartum health care with women's needs, let us review some key aspects of a woman's lifecycle.

\section{Women's Changing Realities}

Programs are founded on the assumption that mothers and other women live under the protection of stable, long-term, co-resident relationships and that parties share the economic responsibility for children. A wide range of data indicate this assumption is substantially false.

Figure 1.1 shows, for countries in various parts of the world, the percentage of evermarried women in their forties whose first union dissolved. Typically, about one-fourth or one-third of the women fall into this category; in three of the countries shown (Ghana, Liberia, and the Dominican Republic), the figure is 50 percent or more.

Figure 1.1

Percentage of Ever-Married Women (Aged 40-49)

Whose First Union has Dissolved ${ }^{a}$

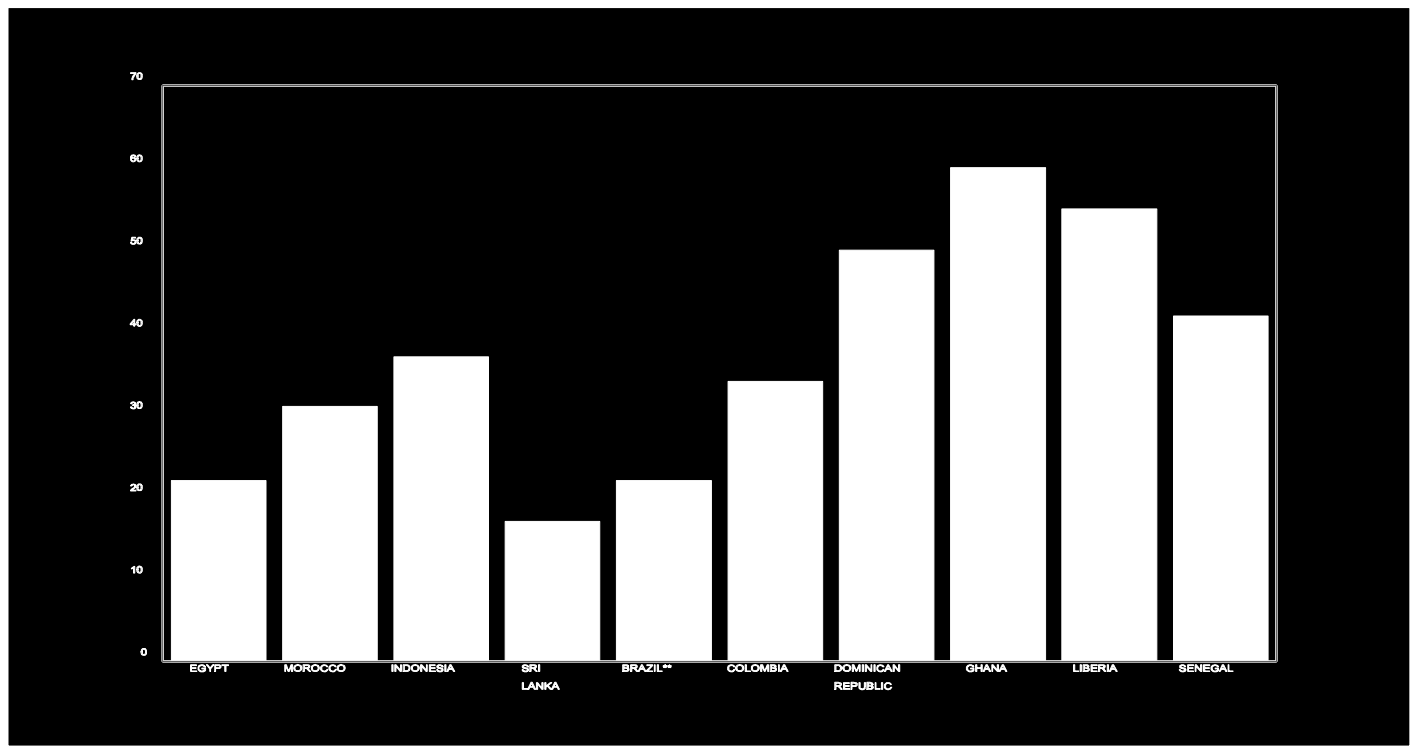

a Marital dissolution includes widowhood, divorce, separation and remarriage Source: Lloyd, C., Family and Gender Issues for Population Policy, 1993.

**Based on ages 40-44 
Unions that produce children are not always marital. Varying high proportions of mothers who have children between 6 and 36 months of age in Latin America and the Caribbean are in consensual unions (e.g., 20 percent for Brazil, 39 percent for Colombia, and 61 percent for the Dominican Republic). Consensual unions are considerably less stable than marriages, and the fathers in such unions may be less committed to their children than fathers in formal unions.

Nor do women who are married necessarily live with their husbands. One way to take this into account and thus get a fuller picture is to look at the proportion of a woman's reproductive years (ages 15-49) spent without a husband in residence (i.e., unmarried, divorced, widowed, or married with the spouse living apart). For example, the proportion of women's reproductive years spent without a husband in residence is 20 percent in Mali, ${ }^{1} 33$ percent in Senegal, 43 percent in Kenya, and 50 percent in Ghana (Lloyd, 1993).

Current trends in migration, economic uncertainty, and political instability serve to increase the volatility of marital and other sexual relationships. Figures like those above are only likely to get higher over time.

With all this change, the relative stability of the mother-child link is striking. The percentages of young children living with their mothers are extremely high (e.g., for children under three years, 96 percent in Thailand, 97 percent in Senegal, 98 percent in Colombia and Ghana, and 99 percent in Mali and Peru).

In part because of the growing volatility of relationships, women are increasingly responsible for supporting households with children. Table 1.1 gives percentages of households "officially" headed by women. The households counted are primarily those in which no adult male is present; therefore, these figures understate the case by excluding the many households in which women provide the chief

\begin{tabular}{|l|c|c|}
\hline \multicolumn{3}{|c|}{$\begin{array}{c}\text { Table 1.1 } \\
\text { Percentage of Households Headed by } \\
\text { Females for Recent Years }\end{array}$} \\
\hline $\mid$ Country & Year & Percentage \\
\hline \hline \multicolumn{1}{|c|}{ Country } & 1981 & 17 \\
Bangladesh & 1985 & 17 \\
Peru & 1980 & 17 \\
Thailand & 1987 & 21 \\
Brazil & 1980 & 22 \\
Dominican Republic & 1980 & 24 \\
Kenya & 1878 & 25 \\
Rwanda & 1990 & 42 \\
Jamaica & \multicolumn{2}{|c|}{} \\
\hline \multicolumn{2}{|c|}{${ }^{2}$ Largely households without adult male } \\
\hline
\end{tabular}

In Mali, women in polygamous unions in compounds are counted as being in residence with husbands. 
economic support and/or are essentially single parents, despite the presence of a male.

Aside from their increasing economic role, women bear a disproportionate responsibility for caring for children, especially young children. For example, it has been calculated that for each child under age one, women typically lose about 10 hours a week of rest or leisure time (Boulier, 1977).

\section{Reproductive Choice}

The concept of reproductive choice is often used too narrowly, to refer to whether a particular pregnancy has been chosen. Within the Ebert Program there is a realization that a broader perspective is needed. Reproductive choice is not a single "choice," but a series of choices. Ideally, "choice" involves voluntary sexual involvement, mutual decision-making about disease and pregnancy prevention, a chosen pregnancy, a supported prepartum period, an attended delivery, a supported postpartum period, and an ongoing sharing between parents of their responsibility for the child.

In reality, for many women some or all of these conditions may not be met, so that sex might be physically or socially coerced and unprotected, the pregnancy unplanned and unwanted, the prepartum period unsupported, the delivery unattended, and the new mother uncared for and essentially alone in meeting the child's needs.

\section{Implications for Postpartum Programs}

Postpartum programs are often designed as if there were a single client with a single goal at a single time-namely, the recently delivered mother whose goal is to practice contraception now. This client exists, but so do many others, as is clear from the preceding discussion of women's lives and reproductive choice.

Although the postpartum period is a rather late event in the series of reproductive choices outlined above, it is not too late for a significant intervention. Postpartum programs can and should (1) affirm and broaden reproductive choice and (2) meet the needs of all involved-the woman, her child, and her partner. It is useful to think of postpartum programs as serving four clients.

Client \#1 is the woman (who happens to have recently delivered a child) who is looking ahead and preparing for her future reproductive, economic, and community life. This client will need support to return to full reproductive and sexual health; guidance on resuming economic, personal, and community roles; and practical information about services. This client overlaps with but is distinct from Client \#2. 
Client \#2 is the recently delivered mother who wants assurance and guidance on appropriate care for herself and her newborn. This client will need check-ups, access to health care for herself and the child, information that will help her take on the new mothering role, and support for decision-making about appropriate infant feeding.

Client \#3 is the infant. The infant needs affection and care from parents; hygiene, safe shelter, and appropriate nutrition; and health care, including immunizations for protection from disease and check-ups to monitor growth.

Client \#4 is the partner of the mother and/or the father of the child. His needs, often overlooked, include support in the following areas: establishing a pattern of caring for the new mother, making necessary economic and social adjustments in the postpartum period, sharing care and responsibility for the new child, reestablishing sexual relations, and using methods for contraception and prevention of sexually transmitted disease (STD).

Providing this broader range of services to this more broadly defined clientele can help people establish lifelong patterns. Thus, the woman learns patterns that encourage selfesteem and decision-making, as well the practical lessons of practicing contraception and caring for herself, and will repeat these beneficial patterns in other birth intervals; the child's long-term well-being is established by patterns of early care; and the partner/father assumes his responsibilities in relation to the woman and child, giving substance to his role and building self-esteem around nurturing others. In this way, such a program would take into account, and try to affect, the changing realities that women face today.

\section{Emphasizing the First Birth}

While improvement of postpartum care is important in all cases, particular emphasis should be placed on the first birth, for several reasons. The first birth is often the most risky from a clinical standpoint, and the most traumatic. First births often coincide with youth and vulnerability; about 40 percent of women are less than 20 years old when they have their first child (Arnold and Blanc, 1990), and many first births are unplanned and unwanted and hence unsupported. Finally, in keeping with the idea of having a long-term impact, emphasis on the first birth helps establish good, long-term habits in reproductive health and child care.

This broadened approach to postpartum health care, in addition to directly benefiting clients, should have important effects on family health, women's empowerment, and voluntary fertility limitation. 


\section{CHAPTER 2: \\ WOMEN-CENTERED SERVICES \\ Huda Zurayk, Chair}

\section{Two Paradigms of Maternity Health Care \\ based on a presentation by Sally Tom}

How should practitioners handle normal, healthy processes of pregnancy, labor, and delivery? Two conflicting paradigms—one dominant, the other a minority paradigm—underlie our Western style of maternity health care in general and of management of labor in particular. Techniques of labor management and maternity care that we export to other cultures are for the most part based on the dominant paradigm. The two paradigms have vastly different implications for clinical practice and allocation of funds and other resources. We need to look closely at these paradigms and their implications before leaping into resource allocation decisions and clinical practice protocols.

The differences in the ways providers respond to the same clinical issues in caring for women in labor demonstrate the existence of the two paradigms. In their book $A$ Guide to Effective Care in Pregnancy and Childbirth, Enkin, et al. (1989) write:

The marked variations that exist in the types of care women receive depend more on which maternity unit a woman happens to attend, and which professional she consults, than on her individual needs or preferences. These differences in practice are often so dramatic that they cannot possibly be explained by differences in medical indications or by the preference of the women attending the different hospitals. (p. 179)

\section{The Dominant Paradigm}

The dominant paradigm in Western medicine sees female reproductive processes as a largely imperfect system, which, if left to its own devices, will likely malfunction and produce a less-than-optimal outcome. The resulting clinical practice, therefore, emphasizes the development and implementation of interventions to reduce the likelihood of bad outcomes. The minority paradigm, in contrast, sees female reproductive processes as a strong and usually competent system, which if given appropriate support for its own devices, will likely work well and produce an optimal outcome. The resulting clinical practice, therefore, emphasizes understanding how and why the system works so well and supporting its 
functioning.

In The Reflective Practitioner, Donald Schön (1983) discusses how medical thinking is dominated by the idea that "professional activity consists in instrumental problem solving made rigorous by the application of scientific theory and technique" (p. 21). He traces this idea to positivism, the nineteenth-century doctrine whose adherents saw empirical science as the only source of positive knowledge, and science and technology as central to humanity's well-being.

These ideas have some problematic consequences. The idea that empirical science provides the only true knowledge leads to the false conviction that the scientific method can resolve all problems and also leads us to neglect other ways of knowing. The emphasis on problem-solving leads to the view, discussed above, of pregnancy, labor, and delivery as problems to be solved, rather than as natural processes to be supported. Research consequently focuses on developing more "instruments" that better solve the "problems" of labor and delivery. Clinical practice rooted in only one form of knowledge deemphasizes or ignores the woman as a person and discounts the psychological and emotional dimensions of her experience. It encourages the application of interventions designed to treat pathology both to healthy and complicated childbearing. The inappropriate use of treatments for illness, in an attempt to prevent pathology from occurring, wastes resources and often can do harm.

Two vignettes from Thailand illustrate some consequences of exporting the techniques and arrangements of the dominant paradigm. Although Thailand has a strong breastfeeding promotion program, a Western-style organization of medicine into specialties and conceptualization of labor as a discrete period, rather than part of a continuum of childbearing, combine to discourage breastfeeding. The first hour after delivery is critical for establishing breastfeeding. Breastfeeding is not considered part of the obstetrician's work, which ends with the stabilization of postpartum bleeding before the woman leaves the delivery area. The pediatrician, who is considered to be responsible for breastfeeding, does not have authority in labor and delivery. Thus, breastfeeding cannot begin, because the mother and infant remain under the authority of the medical specialist who does not see breastfeeding as his or her problem to solve. In a labor ward, supposedly organized along Western lines, women were laid in beds placed in a long row without screens or curtains to separate them; the women had no labor support; most appeared to have epidural anesthesia, and most were receiving pitocin; all appeared to be lying on their backs. Labor has become a production process, and Westerners have a lot of responsibility to take for creating this sorry situation and for changing this perspective on labor. 


\section{The Minority Paradigm}

What, then, of the other paradigm, in which natural reproductive processes receive appropriate support? Although a minority paradigm, it does have a strong toehold in the practice of obstetrics in the United States and may have an even stronger place in some European countries. This paradigm is associated with birth centers, in which healthy women receive nonpharmacological, nontechnological interventions to support their labors, with drugs and other technologies reserved for complicated childbearing.

The National Birth Center Study looked at 12,000 women who enrolled for care at 84 centers around the United States (Rooks, et al., 1989; 1992a-c). The study, which compared hospital and birth center deliveries, concluded that for low-risk, carefully screened women, "care in freestanding birth centers results in equally favorable outcomes as does care given in hospitals." A companion study also found that hospitals were associated with far greater interventions, even though practitioners in the study had a family-centered philosophy of care: "Even for women who demonstrated no complications during either the antepartum or intrapartum period, an aggressive process of labor management was associated with the hospital setting" (Fullerton and Severino, 1992). Furthermore, "this intervention was not associated with more favorable maternal or infant outcome statistics and may have contributed to infant morbidity" (p. 340).

These findings strongly suggest that, rather than blindly exporting the dominant Western paradigm, we need to consider carefully what models of maternal care might be the most appropriate. We should not abandon the study of pathology; we do of course need to know how to intervene when the physiological processes go astray. Nor will birth centers necessarily be the right model for all other places. Rather, we need to focus on what works to support normal labor. As a wealthy Western nation, we have an enormous impact on how other countries structure their health care delivery systems. We have, therefore, a serious obligation to export a different paradigm of care for childbearing women and their families.

\section{Overview of Service Integration:}

Challenges and Possibilities

based on a presentation by Anibal Faúndes

Postpartum services are generally not well integrated, and that can adversely affect the range and quality of services that clients receive. What kinds of integration of postpartum services are possible? What are the obstacles to integration, and how can these obstacles 
be overcome?

Several possibilities are available during the postpartum period:

* Women's health services, such as contraception and cancer prevention, can be integrated with routine postpartum check-up.

* Women's and infant's health services can be combined.

* Breastfeeding promotion can be specifically integrated with counseling on postpartum contraception.

* Continuity of prenatal and delivery care can be linked with postnatal care.

Each potential kind of integration faces a set of obstacles. Although these obstacles often overlap, we can look at the obstacles to each kind of integration in turn.

\section{Obstacles to Service Integration}

Postnatal care provided to women is sometimes limited to a check-up of anatomical recovery. More extensive women's services, including counseling on breastfeeding, cancer prevention, and family planning, when offered at all, are often provided separately. Yet, integration of women's services seems like an obvious step. Why doesn't it occur?

One reason is that health care providers are reluctant to take on new duties, such as breastfeeding promotion or family planning counseling, without an increase in salary. Another is that they sometimes lack the specific expertise that is required. Logistics can be an obstacle to the integration of some services; supplies and equipment needed for one component, such as family planning, may not reach the place where postpartum care is being provided. Finally, in some cases cultural and political prejudice against family planning is an obstacle to its inclusion in programs.

Integration of women's and infant health-care services faces much greater obstacles, as various kinds of professionals are inevitably involved. Obstetricians and pediatricians often work at different hours, so that even coordinating appointments becomes difficult or impossible. A further problem is that health care professionals and clients alike traditionally have placed much greater emphasis on infant care than on women's health.

Integration of breastfeeding promotion with postpartum contraception faces some obstacles already mentioned in discussing the general integration of women's health care services. Other, more specific obstacles center on a lack of information. Pediatricians and 
gynecologists alike are often not fully aware of, or are misinformed about, the value of lactational amenorrhea. They might also lack information on the importance of birth-spacing and/or breastfeeding to infant health. The tendency to overlook a possible role for breastfeeding in contraception is reinforced by a faith in high technology and hence a preference for technological methods.

A main obstacle to the integration of prenatal and postpartum care is the concept that prenatal care is intended essentially to protect the baby, so the need for that care ends with delivery. There is a failure to perceive women's needs in the postpartum period. Women who seek prenatal care often are not aware of the importance of postpartum care, and because their attention is centered on the newborn, they often do not have time to think of themselves. Coordination of obstetric and pediatric appointments is not always easy.

In the face of these obstacles, what can be done to promote these various kinds of integration of services?

\section{Strategies for Integration}

One key strategy will be to exploit existing factors that favor integration. These factors are especially present in the area of women's postpartum services, where the same general staff has the capacity to provide all services and where current underutilization of facilities and equipment means that there is time and space to provide more services.

Several other possible interventions to improve the integration of postpartum services focus on health-care providers. The preceding discussion makes clear the need for more training. In addition to imparting technical skills and specific information, training must also cover health planning and social medicine, to convey to health-care providers the benefits of integration of services. This training should also aim at increasing the motivation of providers to integrate services. They need to understand that through integration of services they can improve their clients' health, reducing pathology, perinatal deaths, and abortions. At a more personal level of motivation, they need to be shown that integration can ultimately reduce their work load and reduce costs. Finally, mechanisms are needed to encourage health providers to continue integration. One such mechanism is ongoing supervision; another is interaction of providers with organized community groups, as providers are not indifferent to community perceptions of the quality of their work.

\section{Conclusion}

Obstacles to the successful integration of various potential postpartum services, 
although real, can be overcome if they are clearly identified and if integration strategies take them into account.

\section{Integrating Mother and Child Health Services in Senegal \\ based on a presentation by Mohamadou Fall}

Senegal, the westernmost point on the African continent, has a population of approximately 7.5 million inhabitants, 62 percent of whom live in rural areas. As in much of sub-Saharan Africa, Senegal suffers from high infant mortality rates, mostly caused by infectious diseases-specifically, respiratory and gastrointestinal ailments. In order to significantly lower infant mortality, the Senegalese health system is focusing its attention on addressing prenatal problems.

The maternal mortality rate is also high $(600 / 100,000)$. The high maternal mortality of mothers during the postpartum period makes it particularly important to improve postpartum care, which is currently poorly managed in Senegal.

\section{The Senegalese Health Care System}

The Senegalese health infrastructure is organized by region, with a total of 10 medical regions serving the entire country. A reference hospital is located in each region. Each district has one health center, which includes a maternity unit, and a family planning center.

In urban centers, limited postpartum services are available at the maternity centers. However, due to their high volume, most of these centers provide only minimal care for mothers and infants. Reference centers in towns, including municipal hospitals and private clinics, tend to be overcrowded, poorly equipped, and inadequately staffed. Mother and infant services are not usually integrated at this level. Babies that are sick at birth are referred to the neonatal unit, which separates them from their mothers and interrupts breastfeeding.

In suburban and rural district health centers, postpartum services are generally poor and tend to be offered only during the very early postpartum period, during the time of cord healing. Again, mother and infant services are not integrated, and family planning activities are separate from infant health care services.

Health posts are located in the villages, and some rural villages have maternity centers, which are supervised by a nurse or midwife. Traditional birth attendants serve as health care providers during delivery and the postpartum period, and they carry out follow-up activities. 


\section{Institute of Pediatric Health}

The Institut de Pediatrie Sociale (Institute of Pediatric Health), located in the suburban area of Pikine, is closely linked with the University Cheikh Anta Diop and the Ministry of Health. Its objectives are to protect mother and child health, to implement appropriate models to improve health, and to train health care providers at all levels. Its programs and initiatives are carried out in national teaching hospitals, suburban health centers, and rural health centers, with a special focus in rural areas on public health strategies. It is implementing a new strategy to integrate maternal and infant health services.

The Ministry of Health and the University actively coordinate their professional services by referring newly delivered mothers to the Pediatric Institute. The Institute, through its suburban and satellite clinics in the area, follows both infants and their mothers through the first year of life. Maternal problems are treated by personnel in the satellite clinics and, as necessary, are referred back to the maternity hospital. This system has provided for continuity of care by integrating postpartum and postnatal care (i.e., maternal care and infant care).

Lessons learned during the past 20 years suggest that the integration of maternal and infant health services is necessary to improve the overall quality of services in communities throughout Senegal. Integrating these services is also the best way to utilize Senegal's scarce health-care resources.

The Pediatric Institute is currently making efforts to integrate maternal and infant care services during the postpartum period. The general health of mother and infant, child growth and development, mother's breast milk availability, nutritional status, immunizations, and family planning needs are all checked and documented during visits that are part of an integrated postpartum health care program for mothers and their babies. Since infant health, breastfeeding, and mother's health are linked, integrated services are used to teach mothers about the benefits of breastfeeding for infant health, how to maintain their own health, proper nutrition, and how to avoid unwanted pregnancies. Postpartum check-ups are arranged at birth, three days, eight to ten days, and then the first, fourth, seventh, twelfth, eighteenth, and twenty-fourth months.

Such integration of services, besides having cost benefits, will provide women with access to family planning services as one component of a "total" health care program for women. Such an approach to service provision will, it is hoped, encourage continued contraceptive use and will make it easier for women to overcome cultural barriers to family planning, since family planning will be seen as part of a broader program aimed at improving 
the overall health of mothers and their babies.

\section{Integrating Postpartum Health Care and Family Planning: The Chilean Experience \\ based on a presentation by Soledad Diaz}

In establishing a program for postpartum health care and family planning services in Chile, we began with two concepts. First, the postpartum period is essentially a transitional stage from pregnancy to a period of relative autonomy for the mother and child. The breast replaces the placenta as a source of nutrition and as a mechanism for conferring immunological and nutritional protection. Breastfeeding also provides a close sensorial interaction between mother and child. Second, it is the mother who is responsible for infant care and for decision-making about her own health and the practice of contraception. The proper role for health-care providers is a supportive one.

The effectiveness of a program based on these concepts was first tested (in June 1991) at the Consultorio de Planificacion, of the Instituto Chileno de Medicina Reproductiva (ICMER), in Santiago, Chile. In its 15 years of operation, this clinic has been devoted to research in contraception, and participants had to meet certain criteria, discussed below. Later (1991-92), a second program was established in Santiago, this time at the Consultorio San Luis de Huechuraba (CSLH), a community-based clinic run by a nongovernmental organization (NGO) involved in health care. The CSLH program is open to all neighborhood women, so that participants are representative of the general population.

\section{Postpartum Services at ICMER}

Maternal-child health $(\mathrm{MCH})$ care is integrated at ICMER. For the convenience of mothers and to reinforce the message that the mother and child are a unit, mothers and their children have the same number of postpartum visits, scheduled on the same days. Mothers and children also have joint files, so the pediatric- and gynecologic-care providers have the same information.

Providers work together as a team. All health workers have the same training in breastfeeding and contraceptive management, and they therefore give clients consistent information. In addition to sharing the information in the joint files, the members of the health team are available to one another for consultation on an ongoing basis, and they meet weekly to coordinate their activities. 
Clients, initially contacted in a maternity ward, meet the following criteria: they are healthy women who had a normal pregnancy and term delivery of a healthy child; they are married or in a regular cohabiting relationship, do not work outside the home, and are willing to breastfeed; and they have no medical contraindications for the use of contraceptives.

Visits are scheduled at $8,20,30,40,55$, and 70 days postpartum and at monthly intervals for the rest of the first year. Women are encouraged to visit any time they have problems or questions. Contraceptive methods are initiated around 55 days postpartum. More recently, an alternative schedule was tried, with the same visits in the first three months but subsequent visits at three-month intervals.

A central component of the program involves education and counseling, which continue throughout the time a woman is in the program and are tailored to meet each woman's needs, as the providers perceive them. In the maternity ward women are given information about breastfeeding and infant care in the immediate postpartum period. The early visits at the clinic reinforce breastfeeding, and at the end of the first month women receive information on contraception for lactating women. (As lactational amenorrhea in Chile tends to be short, no attempt is made to extend its benefits beyond three months.)

Contraceptive choices offered over the years in the ICMER clinic have depended on research projects in the clinic but have been limited to those that will not interfere with lactation or infant growth. Choices have included copper-T IUDs, devices that release progesterone, NORPLANT® implants, progestin-only pills, and barrier methods. When a woman chooses a method, she is counseled on side effects and her experience with the method is evaluated at subsequent visits.

Exclusive breastfeeding on demand is promoted during the first six months. The women are encouraged to keep a daily record of the number of day and night feeds. Milk supplements are prescribed only if the infant growth curve is altered; nondairy meals are introduced after six months.

\section{Outcomes at ICMER}

Contraceptive performance, breastfeeding duration, and infant growth and health have been assessed quantitatively during the 15 years of the program. In addition, an outside team has assessed the program qualitatively, through in-depth interviews and focus group discussions with clients and interviews with staff.

In general, contraception continuation rates at the end of the first year are above 96 percent, and in some studies they reach 100 percent. Clients lost to follow-up range from 
less than 1 percent for those using long-term methods such as IUDs and NORPLANT® to around 5 percent for those using progestin-only pills. One possible contributor to the high continuation rates is the fact that, as contraception is begun during the period of lactational amenorrhea, menstrual irregularities are not a problem.

The proportion of women who are breastfeeding has been consistently around 90 percent at the end of six months and around 55 percent at the end of 12 months. The proportion of women exclusively breastfeeding at six months has remained in the range of 50 to 60 percent. In contrast, in studies of the general population of Santiago, at six months postpartum no cases were exclusively breastfeeding and only 50 to 60 percent were breastfeeding at all.

Preliminary results suggest that outcomes for contraception and breastfeeding are similar in the alternative schedule, with fewer visits after three months.

The growth and health of the breastfed infants have been extremely positive. There has been one infant death in over 5,000 cases, a significant contrast with the infant mortality rate in Santiago, which ranged from 17 to 30 per 1,000 in the same period. Rates for diarrhea, respiratory disease, and nutritional problems were also very low, especially during exclusive breastfeeding.

The qualitative assessments showed that women are pleased both with the information and support provided and with the way the staff treat them. They expressed the view that the work they did (e.g., in keeping the breastfeeding records) and the way they were treated promoted self-esteem.

\section{Postpartum Services and Outcomes at CSLH}

In view of its success, the program is now also being tested in a different setting without the research constraints of ICMER. The Consultorio San Luis de Huechuraba is in a poor neighborhood in Santiago and is part of an NGO involved in community health work.

All pregnant women in the neighborhood are contacted by a community health worker and invited to the Consultorio. Almost 100 percent of the women contacted have enrolled. Education is initiated during this first contact. Postpartum visits are scheduled as at ICMER. Women decide when to initiate contraception; 87 percent of the women enrolled have done so in the second month postpartum. IUDs and progestin-only pills have been the preferred choices.

Preliminary results show significant differences between the CSLH and a state clinic in a similar, nearby neighborhood. At six months postpartum, 98 percent of the women at the 
CSLH were breastfeeding, but only 62 percent were breastfeeding at the state clinic. The figures for exclusive breastfeeding were 42 versus 0 percent, respectively. Not surprisingly, infant health measures, like diarrhea rates and mean weight, also differed substantially.

\section{Conclusion}

The integration of postpartum care and family planning services at two clinics in Chile has generally resulted in satisfied clients, high contraceptive continuation rates, good followup, lower infant mortality and good infant health, increased knowledge about the nutritional (for the infant) and contraceptive benefits of breastfeeding, and longer duration of breastfeeding. 


\section{CHAPTER 3: \\ RESPONDING TO WOMEN'S NEEDS: WHEN DO WOMEN CHOOSE SERVICES? Kathryn Tolbert, Chair}

\section{Overview of the Timing Dilemma \\ based on a presentation by Barbara Mensch}

By and large we don't know what services women want in the postpartum period or when they want these services. Data on women's desires regarding timing and type of contraception are only beginning to be collected. Therefore, it is impossible to make definitive statements about when women would choose services if given a choice. What is appropriate and possible at this point is an overview of the timing issues that have emerged in investigations of postpartum family planning programs. In particular, we need to look at the strategy of contraceptive service delivery during the immediate postpartum period and at its underlying assumptions, and to see whether the data that do exist support this strategy or an alternative strategy that delays contraception until later in the postpartum period.

The immediate postpartum model assumes (1) that earlier contraception is associated with a longer subsequent birth interval; (2) that women are most motivated to practice contraception in the immediate postpartum period; and (3) that once women have left the hospital, they are unlikely to return for services. Let's look at each assumption in turn.

\section{Effect on Birth Interval}

Since ovulation may precede the return of menses, many argue that immediate initiation of contraception eliminates the risk of unprotected intercourse and thus produces the longest birth intervals in a population. The sparse evidence available suggests that in many situations this assumption about birth intervals might not be supported. Studies (Bhatia, et al., 1984) from Bangladesh have shown that women who accepted oral contraceptives during lactational amenorrhea were more likely to be pregnant at 18 months postpartum than were later initiators, because they also abandoned contraception earlier in the postpartum period and experienced shorter amenorrhea. Zimbabwe, for example, has both high fertility and relatively high contraceptive prevalence, evidently because of extensive overlap between amenorrhea and contraceptive use.

Because of the lack of data, demographers have used simulation models to explore the effect that timing of contraceptive adoption has on birth intervals. A recent model, 
developed by Michael Bracher (1992), looks at the intervals that would result from three hypothetical timing patterns: (1) adoption of contraception at six weeks; (2) use of the lactational amenorrhea method (LAM), with adoption at cessation of full breastfeeding, the return of menses, or six months postpartum, whichever comes first; (3) LAM with delay, in which contraception is not adopted when its need is first indicated, whether because of misunderstanding of LAM or because of contraceptive supply problems. (For this delay category, one-third of all women adopt as prescribed, one-third delay for one cycle, and onethird delay for two cycles.)

As can be seen in Figure 3.1, compared with adoption at six weeks, LAM does not result in a greater percentage of short intervals. When the discontinuation rate is high, LAM does particularly well, a result consistent with the Bangladesh and Zimbabwe data. It can be concluded, then, that in many situations the postpartum strategy is not advantageous on demographic grounds alone, assuming LAM is practiced correctly.

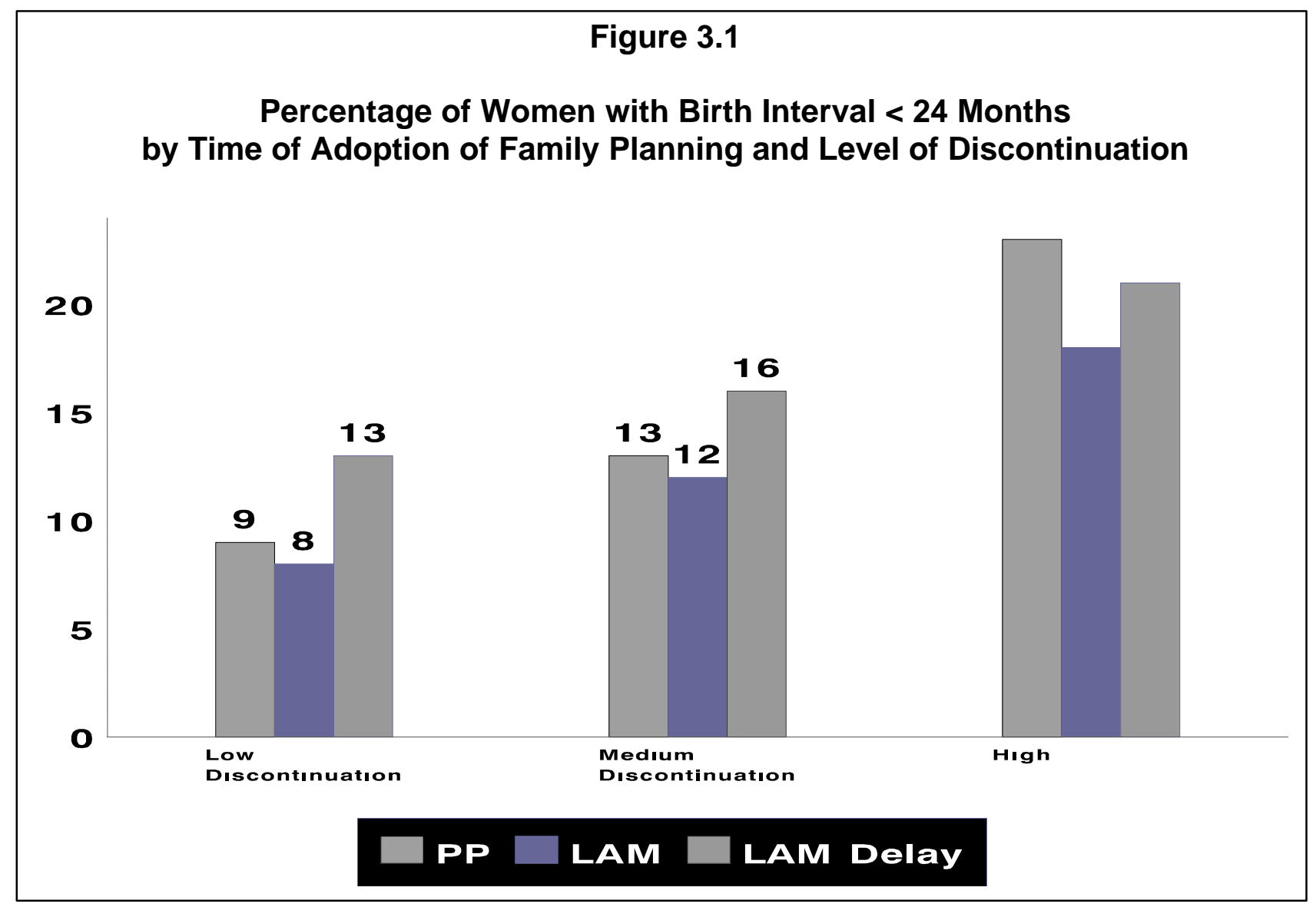




\section{Timing of Maximal Motivation}

It has often been assumed that motivation to practice contraception is highest immediately following childbirth because of the unpleasantness of childbirth and/or because women are worried about having another child too soon. Data on this behavioral assumption are not available. Few surveys have addressed women's preferences or their priorities in the postpartum period.

The large number of acceptors in immediate postpartum programs is sometimes taken as evidence that women are highly motivated at this point. But these numbers could also be explained by a lack of alternative opportunities or even persuasion to accept a method at delivery.

A few studies have looked at whether there might be links between the initiation of contraception and other events in a woman's life, such as the return of menses or the end of breastfeeding. For example, Laukaran and Winikoff (1985) have shown that in urban areas of Thailand, Indonesia, Kenya, and Colombia, women whose menses had returned were much more likely to be practicing contraception than women who had not yet resumed menstruating.

In the 1987 Thai Demographic and Health Survey (DHS), women were actually asked about the timing of initiation of contraceptive use relative to menses. As Table 3.1 shows, among women who adopted some method other than sterilization, a large majority initiated use after menses. What is most striking is the percentage who initiate use during the same week as the return of menses. To some extent this relationship may be an artifact of

\begin{tabular}{|c|c|c|c|c|c|}
\hline \multicolumn{6}{|c|}{$\begin{array}{c}\text { Table } 3.1 \\
\text { Timing of Contraception by Method } \\
\text { Thailand DHS, } 1987\end{array}$} \\
\hline & $\begin{array}{c}\text { Female } \\
\text { sterilization }\end{array}$ & Pill & IUD & Injectables & Other \\
\hline Before menses & 97 & 14 & 36 & 16 & 32 \\
\hline After menses & 3 & 86 & 64 & 84 & 68 \\
\hline $\begin{array}{l}\text { Same weeks as } \\
\text { menses }\end{array}$ & 0 & 48 & 37 & 45 & 21 \\
\hline Source: Knodel, J. and & N. Chayovan, 1989 & & & & \\
\hline
\end{tabular}


program policies. For example, clients are advised to start pill use on the fifth day after a period begins, and providers may be reluctant to offer IUDs and injectables unless assured by the return of menses that the woman is not pregnant. But the "other" category, which includes condoms and spermicides, shows a similar pattern. So the resumption of menstruation does seem to be taken as a sign of fertility and to prompt women to initiate contraception.

Breastfeeding status has been shown to be inversely associated with contraception, although this might simply be a function of the relationship between breastfeeding and postpartum amenorrhea. In any case, it might well be that maximal motivation coincides not with delivery but with subsequent events in the woman's life. In addition to events discussed here, other possibilities include return to sexual activity or even return to other activities or the developmental stage of the infant.

\section{Returning for Services}

Because health facilities are often inaccessible, transportation inadequate, and the demands on women onerous, women who have recently delivered are thought unlikely to return to a service delivery point. Although the evidence is limited, it seems quite possible that women would return, especially if other health services are also offered. For example, when the International Postpartum Program, begun by the Population Council in the 1960s, introduced postpartum family planning, average return rates of women for postpartum checkups in participating hospitals rose from 13 to 41 percent. Family planning was seen as the "carrot" that led to increased return rates. However, routine postpartum exams had not been offered prior to the program's establishment, and it is likely that this service was a large part of the incentive (especially as 35 percent of those who returned did not accept a method). While information on return for postpartum checkups is rarely collected, recent data from selected countries suggest that many women will return to health care facilities following childbirth. (See Table 3.2.)

\begin{tabular}{|c|c|c|c|}
\hline \multicolumn{4}{|c|}{$\begin{array}{c}\text { Table } 3.2 \\
\text { Return for Postpartum Check-up }\end{array}$} \\
\hline Place & $\mathbf{N}$ & Date & $\begin{array}{l}\text { Percentage } \\
\text { return }\end{array}$ \\
\hline Botswana $^{a}$ & 3,177 & $1983-88$ & 71 \\
\hline Tunisia $^{b}$ & 9,240 & 1987 & 83 \\
\hline Honduras $^{c}$ & 688 & 1987 & $75-80$ \\
\hline Ecuador $^{d}$ & 2,036 & $1982-87$ & 38 \\
\hline
\end{tabular}




\section{Conclusion}

While the data are scarce, the assumptions underlying the immediate postpartum strategy are, at best, not universally supported and, at worst, questionable. However, this discussion is not intended as a complete rejection of that strategy. Rather, it is likely that women manifest various desires and behavior in the postpartum period, so that a variety of strategies are needed. This notion argues for a program that provides contraceptive information at all times and that offers family planning services at delivery and anytime thereafter. Just as we promote choice of methods, so we should promote choice of timing. Moreover, the two choices should be separate: the type of methods offered should not depend on the timing of the offer.

\section{Client and Provider Perspectives on Postpartum Contraception} based on a presentation by Cynthia Steele Verme

Interest is growing in providing family planning information and services to women during the perinatal period, from pregnancy through postpartum, because that is a time when many women are in contact with the health system. As the Association for Voluntary Surgical Contraception (AVSC) supports postpartum contraception services in different parts of the world, it undertook to learn how best to provide women with these services and the relevant information.

The research described here looked at client attitudes and preferences, at provider attitudes, and at the actualities of service delivery. The specific objectives were to learn about (1) the type of information, if any, women receive about contraceptives when they receive prenatal care; (2) the kind of family planning information and services women in the perinatal period-i.e., the period covering antenatal, intrapartum, and through the first postpartum visit-would like to have; and (3) the attitudes and practices of maternity hospital service providers regarding postpartum contraception. The findings are being used by AVSC and the programs where the research took place to improve staff training, materials, and services and to orient services, including education and counseling, more to clients' needs and interests.

\section{Study Design}

The study was carried out in six countries where AVSC is supporting institutions that plan to expand postpartum contraception services: Colombia, the Dominican Republic, 
Kenya, Mali, India, and Turkey. The institutions are maternity hospitals in mostly urban areas. The Program for Appropriate Technology in Health (PATH) and Family Health International (FHI) collaborated with AVSC in Mali and Kenya.

In each country, data were obtained through focus group discussions with pregnant women, structured interviews with 100 postpartum women before their discharge from the hospital, interviews with about 25 service providers, and questionnaires on services provided by the institution.

(For reasons of space, differences among countries are largely ignored here in favor of the overall patterns; however, these differences were sometimes considerable.)

\section{Background Information on Respondents}

The respondents were typically young (mean age of 23-26) married women with an average of two to three living children. Most had a primary level of education or less; few worked outside the home.

Most of the women received prenatal care. Awareness of family planning methods was quite high, although past use of methods varied widely (from 24 percent in Mali to 62 percent in Turkey) and a troubling proportion of women reported becoming pregnant while practicing contraception. Roughly one-third to two-thirds of the women in the various countries had not wanted to have a child at the time they became pregnant. In terms of future fertility preferences, over half of the women in Kenya and Mali want more children, whereas three-fourths of the women in the Dominican Republic, India, and Turkey do not.

\section{Findings}

The need for early postpartum contraception is linked to factors including return of fecundity and resumption of sexual activity. Very few respondents regarded the first menses as a time to initiate contraception. In most countries, clients and providers alike mentioned a 40-day waiting period before resumption of sexual activity. Nonetheless, it appears that practices might be different from the stated norms, especially as many women said they did not want to refuse their husbands.

Women gave a range of answers in response to the question of when they preferred family planning information to be provided. Preferred times included prior to pregnancy, during the prenatal period, and/or prior to discharge from the hospital-essentially, all times other than during labor.

The responses of service providers were largely similar to those of the women, with 
two partial exceptions. The service providers tended to object less to labor as a time for providing information, and they also tended somewhat less to view the prenatal period as a crucial time for providing information. Yet the majority did feel information should be given at all possible opportunities except during labor.

Postpartum women were asked whether they received family planning information during pregnancy and/or their hospital stay. With the exception of Kenya and Mali, where postpartum IUD projects have been introduced, many more women were interested in receiving information than actually received it. There are some discrepancies between provider and client reports. In one hospital where an administrator said all women receive family planning information before discharge, only two of the postpartum women interviewed reported receiving information.

Provision of methods also appeared to fall far short of demand. Among women who reported that they did not want more children, about one-fifth left the hospital with a method. With the exception of Mali, where a significant percentage of women plan to initiate contraception within a week of discharge, the vast majority of women who want to use a method but left the hospital without one plan to initiate contraception either after four to six weeks or at some other point within six months. Many of these women were not aware of or did not have access to immediate postpartum contraception.

In Colombia, the Dominican Republic, India, and Turkey, a minority of women who had planned to use either sterilization or an IUD in fact left the hospital with the method. Among women who intend to use an IUD, the main reason given for leaving without one was that postpartum IUDs were not available. Among women who wanted but did not get sterilization services, the principal reasons given included not having made the arrangements before delivery, being told the service was not available at that time, health problems, and not knowing postpartum sterilization was an option.

\section{Conclusions}

The research highlights a need for service providers to better understand women's preferences regarding the provision of contraception information and services in the perinatal period. For example, client preferences suggest that more emphasis should be placed on providing information during prenatal visits. This finding, together with the inconsistencies in reports from staff and clients about whether information was provided, points to an unmet need for information. Given women's interest in receiving information after the delivery and before hospital discharge, the research also suggests programmatic interventions to work 
around the constraints of hospital time and staff.

It is important that the information provided be consistent and accurate and address clients' concerns. The research showed that women's chief concerns, which often go unaddressed, include the effect of contraception on their breast milk and on their health. Moreover, the research findings showed widely varying guidelines for contraceptive use in the postpartum period, which suggests that providers should be continually updated on postpartum contraceptive technology.

Although clients and providers agreed that prenatal and postpartum check-ups are good times for providing information, a key challenge will be meeting the information and service needs of women who don't come to the hospital for check-ups but only to deliver.

If the demand for immediate postpartum contraception is to be met, several obstacles must be overcome. Providers need to make clear that the services exist; they need to make them more available; and counselors working with pregnant women need to help interested clients do what is bureaucratically necessary to implement their decision.

Finally, the research showed major differences, not only among providers and clients, but also among countries. Country and site differences must be taken into account in putting programmatic approaches into place. More generally, the differences argue for not polarizing the debate on postpartum contraception and for learning to better meet the needs of a wide range of clients.

\section{Timing and Content of Services: \\ Lessons of the Honduran Social Security Institute}

based on a presentation by Rebecka Lundgren

The results of an operations research (OR) project undertaken by the Honduran Social Security Institute (IHSS) shed some light on the timing and content of reproductive health and family planning services might best meet women's needs.

The project emerged from the desire of the IHSS to improve the quality of its services and to increase contraceptive acceptance among women delivering at its hospital. A low level of acceptance was attributed to several factors:

1. Although over 70 percent of women delivering at the IHSS attended five prenatal sessions, no education on reproductive health and family planning was provided.

2. Contraceptive methods were offered only following birth. 
3. Only two options-IUDs and sterilization-were offered (and initially sterilization had been the only option).

The Institute's reproductive health program (RHP) was thus designed to provide education and provide more options both in timing and content of contraceptive services. The program includes a perinatal information system, a prenatal education program, family planning and reproductive health counseling, a 40-day postpartum clinic, and an increased range of contraceptive options.

The effects of the RHP on contraceptive acceptance rates and client knowledge and satisfaction have been assessed through the perinatal clinic history, qualitative studies, preand post-tests, service statistics, and a range of surveys. Four rounds of surveys in the postpartum hospital area were conducted to help provide longitudinal data. The assessment took place over a 12-month period, from February 1991 to February 1992. As it took almost a year to implement the entire program, data presented for one point in time may not reflect the impact of all program components.

\section{Perinatal Information System}

Service providers track events during pregnancy, birth, and the immediate postpartum period (e.g., attendance at educational sessions and contraceptive acceptance). Each woman keeps a carnet (ID card), which is a copy of the patient's clinic history.

\section{Prenatal Education Program}

Women receiving prenatal care at the IHSS facilities may attend six educational sessions, each on a different topic. The session topics are reproductive risk, family planning, prenatal care, breastfeeding, labor and delivery, and baby care. Each session features a presentation by a nurse, a video show, and a brochure. At the sessions, women are invited to attend the counseling service and/or to request a contraceptive method before discharge from the hospital or at the 40-day postpartum check-up.

Attendance ranged, depending on the topic, from about 40 percent (breastfeeding, baby care) to 56 percent (reproductive risk, family planning) of all women delivering at the hospital. Surveys and pre- and post-tests showed that the program resulted in considerable increases in women's knowledge in all areas covered. For example, over the course of the study women were able to mention more reproductive risk factors, and the percentage of women who believed exclusive breastfeeding could serve as a birth-spacing method rose. 
There were also differences in behavior, with the mean number of months of exclusive breastfeeding increasing from 4.3 to 5.8 .

\section{Family Planning and Reproductive Health Counseling}

The program includes a full-time counseling service, and the number of services provided increased steadily. Moreover, although initially only pregnant women attending prenatal sessions were served, counseling was extended to other areas of the clinic and hospital. At the end of the study, women in the postpartum period represented 54 percent of the service's clients, and women in the interval period represented 18 percent. Total clients seen per month had increased steadily over a nine-month period from about 30 to nearly 300 .

This component of the program was also successful in that 98 percent of the women who received counseling opted to use a family planning method. The methods most frequently chosen were sterilization ( 30 percent), IUDs ( 16 percent), mini-pills (35 percent), and combined pills (9 percent).

\section{Forty-day Postpartum Clinic}

A 40-day mother-child clinic was established to resolve two problems. First, in the past only 15 percent of women returned for their postpartum visit, a figure that was at least partly attributable to the scheduling of four separate visits during the first 45 days postpartum and that contrasted sharply with an 80 percent attendance at a 30-day newborn visit. Second, as already mentioned, acceptance of methods immediately postpartum was quite low. Hence, it was decided to have one combined visit at which contraceptive services could also be provided. Even though, in fact, a single clinic did not jointly care for the mother and child, because the obstetrics/gynecology and pediatrics departments are separate, functional integration was achieved by scheduling the mother's and child's appointments for the same day.

During the period of the study, the proportion of women delivering at the IHSS hospital who attended the clinic rose substantially, from 34 percent in August-October 1991 to 45 percent in January-February 1992. A survey conducted in February-March 1992 showed that only 19 percent of the women attending the clinic were already using a method and that 61 percent of the women attending accepted a method during their visit (mainly the IUD [34 percent] and the mini-pill [51 percent]). 


\section{Increased Range of Methods}

To better serve its clients, the IHSS increased the range of methods available after delivery to include mini-pills, condoms, and vaginal tablets, in addition to the IUD and sterilization options already offered.

\section{Conclusions}

Surveys supported the idea that women's satisfaction with the perinatal services provided by the IHSS increased as a result of the reproductive health program. Satisfaction scores for the various program components improved over the assessment period. The establishment of the education program appeared to be an especially important factor.

Contraceptive acceptance rates among women delivering at the IHSS increased dramatically, from 9 percent at the beginning of the program (December 1990) to 46 percent in February 1992. This increase was the result both of increased acceptance before discharge and of the new possibility of accepting contraception at the 40-day clinic. Data suggest that 25 percent of the women accepted a method before discharge while 21 percent did so at the 40-day clinic. The introduction of oral contraceptives seems to have been a major factor in increased acceptance, since by February 1992 they were the method chosen by nearly 30 percent of the women who accepted a method before discharge and by over 50 percent of those who accepted a method at the clinic.

Several conclusions are suggested by an examination of the RHP components and their impact on women's satisfaction and contraceptive acceptance. Women want more complete information throughout the perinatal period. IHSS clients at all stages of the perinatal period used the counseling service. Family planning services should offer options both in timing and content. The expansion of choices to include mini-pills, pills, and condoms increased contraceptive acceptance. An even greater increase resulted from women's option of selecting a method at 40 days postpartum. The inclusion of this timing alternative to immediate postpartum was also supported by the fact that, when services were changed to better meet their needs, many women returned for the 40-day clinic.

\section{Appropriate Technology: A Randomized, Controlled Trial of the "Kangaroo Mother Method" in Ecuador based on a presentation by Nancy Sloan}

Worldwide, low birthweight is a prevalent problem. Neonatal intensive care is 
expensive and, in developing countries, is problematic due to the short supply of incubators and unstable electricity.

In 1979, in response to this problem, Colombian doctors Martinez and Rey developed an ambulatory method for the care of low-birthweight infants called "The Kangaroo Mother Method." The method is founded on three attributes to be provided to the low-birthweight neonate: breastfeeding, heat, and love. It entails holding the baby 24 hours a day, skin-toskin against the mother, breastfeeding on demand, and love.

The rationale behind the creation of this method was:

* to reduce nosocomial infections: the incidence of nosocomial infections is high in developing countries, where more than one neonate are often placed together in an incubator due to the inadequate supply of incubators in most hospitals;

* to reduce the duration of hospitalization by reducing nosocomial infections;

* to reduce the cost of neonatal intensive care by reducing the duration of hospitalization and by shifting some responsibilities of neonatal care from the hospital staff to the mother;

* to promote breastfeeding and to provide a constant source of heat, by 24-hour- aday, skin-to-skin contact with the mother; and

* to promote parental participation and to strengthen parental love and responsibility for the high-risk neonate.

The positive attributes of the method are that it promotes bonding, breastfeeding, and well-baby visits, which all are beneficial postnatal activities. However, the postpartum consequences could be conceived as threatening, as increasing parental responsibility for a precarious infant, as physically demanding (because the mother must maintain the infant in an upright position against her chest 24 hours a day), as a drain on the mother's time for herself and her family, and as a restriction on the mother's earning capacity.

While this method has been widely studied, many of the studies have used uncontrolled designs, very small sample sizes ( $<30$ children in each study group), or historical controls. The historical-control studies generally compared the outcome of all low-birthweight infants born in an institution in one year with low-birthweight infants deemed eligible for assignment to the Kangaroo Mother Method in the following year. The eligibility criteria included factors like stability of temperature and no weight loss over a period of days, and the absence of certain conditions, most notably those associated with higher mortality. In 
essence, these studies compared the mortality rates of a group of survivors and nonsurvivors, the control group, with the mortality rates of a group of survivors, the "Kangaroo children," and found a difference in mortality! In fact, the method, which is promoted as a way to reduce infant mortality, probably has no effect on mortality simply because the eligibility criteria for assignment to the method by definition exclude all early neonatal deaths, which account for the vast majority of all neonatal deaths. Regardless of the questionable quality of these past studies, the method is now commonly recommended and used throughout Latin America and is beginning to be recommended in other parts of the world, as well.

A group of physicians from the Maternidad Isidro Ayora in Quito, Ecuador, were interested in conducting a study of the method. Through the MotherCare program, the Population Council assisted this group in designing and conducting a randomized controlled trial of the method, which applied identical study eligibility criteria to the Kangaroo and control groups. The objectives of the study are to assess the effects of the method on infant morbidity, growth and cost of care. All study subjects are followed up through six months of age.

Preliminary analyses are currently being run, although infants enrolled in the study continue to be followed up. Therefore, the data presented here are preliminary, incomplete, and censored.

\section{Study Findings to Date}

Thus far, study investigators have found the characteristics of both groups to be fairly similar: gender, birth weight, gestation, Apgar scores, weight at eligibility, abnormal observations, percent in incubator on day of eligibility. Some differences, however, in age at eligibility and severe morbidity prior to eligibility were observed. (Controls were slightly older and had more pre-eligibility severe conditions.)

Surprisingly, the mother's sense of security about taking care of her child has been the same in the two groups. As expected, the Kangaroo mothers expressed more difficulty with the method of care, particularly complaining of backaches. Fathers' feelings about their child's method of care have not varied by group, with most fathers expressing great satisfaction with the method. Skin-to-skin contact was reported to occur only in the Kangaroo group, but less than 40 percent of the women continued skin-to-skin contact by 42 days of life, and almost no one continued this contact through 61 days of life. 
A large difference in breast contact has been observed, with the mothers in the Kangaroo group having much more contact through 61 days of life. Oddly, the frequency of daytime and nighttime breastfeeding is not different between groups. Sleeping contact, however, is very different, with Kangaroo babies sleeping together with their mothers more than controls. This continues past the third month of life.

Growth is somewhat better in the Kangaroo group, with about a $150 \mathrm{~g}$ to $200 \mathrm{~g}$ increment seen between the third and sixth month of life.

No differences in mild or moderate morbidity conditions were observed between groups, but the difference in the cumulative incidence of severe illness, mostly lower respiratory tract infection, was striking and highly significant from the second month of life onward. Controlling for pre-eligibility differences in severe morbidity reduced the magnitude and significance of this association very slightly (from $p<0.002$ to $p<0.005$ ).

There was no difference in the cumulative incidence of mortality (only six cases have been reported to date), although control children tended to die younger. The cumulative incidence of rehospitalization was slightly greater among control than Kangaroo children.

Costs of neonatal care, estimated by length of stay, were not different between the groups, although costs of postneonatal care-that is costs to the family-appear to be higher in the Kangaroo group, due to the fact that these mothers take their babies for more frequent well-baby visits than do control mothers.

\section{Conclusions}

What do these findings mean? The lack of differences in mild and moderate morbidity may simply be a function of their definition; mild morbidity includes all common illnesses, while moderate morbidity includes only urinary tract infections. If there are no differences in breastfeeding, and if skin-to-skin contact is basically terminated before two months of age, why are the differences in growth and severe morbidity observed only after two months of age? If breastfeeding or heat or not the reasons, the conclusion is probably the love factor. After all, the Kangaroo mothers had much more sleeping contact with their infants through four to five months of age, and tended to bring their children back for well-baby visits more than did the control mothers-even though it cost them money and time. In fact, what I had originally thought was an imposition on postpartum women-that is, the transference of responsibility for a neonate in a precarious condition to the mother-seems to have resulted in a greater assumption of responsibility, caring, and possibly bonding between the mother and child. Therefore, it is quite possible that this "love factor" may be responsible for the 
observed differences in growth and severe morbidity.

Due to these findings, we have stopped enrollment of new subjects, but we are continuing to follow up those already enrolled in the study. Still, given the statistical chance that this sample is not representative of the general population from which it was drawn and the fact that some pre-eligibility differences were found between groups, the study requires replication. 


\title{
CHAPTER 4: \\ INTEGRATING BREASTFEEDING INTO BIRTH-SPACING STRATEGIES Martha Brady, Chair
}

\author{
Effects of Breastfeeding on Maternal Health \\ based on a presentation by Kathleen M. Rasmussen
}

It has long been known that breastfeeding benefits infants, and that it can even mean the difference between life and death. It is also known that breastfeeding benefits society, offering more woman-years of contraceptive protection in many countries than all other methods combined. Much less, however, is known about the costs and benefits of breastfeeding for mothers. Although formal cost-benefit analyses are not possible, research that has been conducted at Cornell University, in animal models and human subjects, has led to important new concepts that permit some informed judgments about the effects of breastfeeding on maternal health.

\section{Depletion and Repletion}

Across a woman's reproductive years, does lactation represent a net benefit or detriment to the mother? To address this question, it is useful to take the reproductive cycle as our unit of analysis. We can then sum the costs and benefits of individual cycles for a particular woman. The length of a reproductive cycle is defined in terms of the birth interval. Each cycle will include depletion and repletion periods.

Full breastfeeding is recognized as a period of depletion among well-nourished women, who typically lose $0.5-1 \mathrm{~kg} /$ month while nursing. The degree to which breastfeeding is depleting for malnourished women is less clear.

The period during which the woman is neither pregnant nor lactating - the NP/NL interval-has long been recognized as providing an opportunity for recuperation. An important new insight, which emerged from our studies with animals, is that partial breastfeeding also can be part of the repletion period. In experiments with normally fed and malnourished rats, the most malnourished rats actually gained weight while nursing pups (Rasmussen and Fischbeck, 1987).

What happens in humans? A study by Anna Winkvist (1992) looked at data on Pakistani women for whom information on weight change across a complete birth interval was available. Women were categorized as being of high, medium, or low weight at the birth 
of the first study child, with 60 percent of the women in the last group characterized as suffering from chronic energy deficiency. One of the study findings was that during partial breastfeeding the low-weight women maintained their weight, rather than losing weight as might have been expected. This study, then, supports the notions that various periods of the reproductive cycle have different consequences for maternal health and that repletion is possible during more than just the NP/NL interval.

\section{Do Nutritional Supplements for Nursing Mothers Reduce the Contraceptive Benefits of Breastfeeding?}

Like lactation, poor nutritional status is associated with a longer period of postpartum amenorrhea and, as Michelle McGuire (McGuire, et al., 1992) has demonstrated in rats, amenorrhea is further lengthened when both are present. A possible inference is that improving lactating women's nutritional status might shorten the period of contraceptive benefit provided by lactation. This inference seems supported by supplementation studies. However, in these studies, infants over three months of age also received food supplements, which are known to reduce the suckling stimulus. Kathleen Kurz (Kurz, et al., 1993), using data from the Institute of Nutrition of Central America and Panama (INCAP) supplementation trial, was the first to account for this effect. When the child's intake was accounted for, improved maternal nutrition (as reflected by supplement intake and by a change in skinfold thickness) did shorten postpartum amenorrhea, but to such a small extent that a woman would not have time to bear even one additional child during her reproductive lifetime.

There is reason to think that providing food supplements to poorly nourished women will improve their health and the health of their infants. Lactation is very nutritionally demanding for the mother, more so than pregnancy. Infants breastfed by poorly nourished women do not grow well. This is particularly true during seasonal periods of food shortage, when mothers, who lose weight at a rapid rate to subsidize lactation, produce less milk and produce milk that is of lower caloric density.

In a study by Tere González-Cossío (González-Cossío, et al., 1991) to test the effects of food supplementation, poorly nourished Guatemalan women were offered a low- or highenergy cookie six days a week between week five and twenty-five of lactation. Milk production improved in both groups, but especially in the high-energy group. The difference between the groups was greatest for women with poorer initial nutritional status. Milk energy output, the product of volume and composition, is more important than volume for infant health. Although this measure did not differ significantly for the two groups overall, the 
differences were significant for the women with poorer nutritional status. A final and very important result was that, especially among the women with poorer nutritional status, a greater proportion of the high-energy group was able to exclusively breastfeed their infants. This has important implications not only for infant health, but also for contraception. Because the length of exclusive breastfeeding is such an important determinant of the length of postpartum amenorrhea, it is less likely than it has previously appeared that supplementing needy mothers would reduce the effectiveness of breastfeeding as a contraceptive. Further research is needed to document this contention.

\section{Conclusion}

In terms of nutrition, the answer to the question of whether breastfeeding is a net benefit or detriment for mothers seems to depend on how long the woman breastfeeds, on how much of it is exclusive breastfeeding, and on her specific food intake. Whereas exclusive breastfeeding is depleting, partial breastfeeding actually provides an opportunity for repletion, so that over time the net energy balance shifts in the mother's favor.

Women who are sufficiently well nourished to breastfeed exclusively maximize the contraceptive potential of breastfeeding. Furthermore, it appears likely that partial breastfeeding makes an independent if less powerful contribution to the contraceptive effectiveness of breastfeeding.

We should improve the nutritional status of women in whom breastfeeding might be depleting, rather than advising them not to breastfeed. Such an approach will simultaneously improve maternal health, benefit infant health, and continue the contraceptive benefits of breastfeeding.

\section{The Role of Breastfeeding in Fertility Regulation}

based on a presentation by Kathleen Kennedy

In order to describe the role of breastfeeding in fertility regulation, five themes need to be covered.

Breastfeeding has a profound demographic effect. It postpones the return of fertility postpartum, and it can be argued that breastfeeding reduces or at least delays the need for postpartum contraception.

* It is accepted that there is a biological basis for the mechanism of fertility reduction during breastfeeding. 
* Not only is the return of fertility unintentionally delayed during breastfeeding, but individual women can intentionally use lactational amenorrhea as a contraceptive.

- Breastfeeding affects the choice of a contraceptive.

* Unchallenged assumptions exist concerning breastfeeding, the postpartum period, and postpartum contraception.

\section{The Demographic Effect of Breastfeeding}

The first theme to address is the demographic effect of breastfeeding. Figure 4.1 is based on World Fertility Survey data from the 1980s.

\section{Figure 4.1}

\section{Percentage of Fertility to Total Fecundity and Percentage of Fecundity Reduced Due to Breastfeeding, Contraceptive Use, and Marital Factors, by Rural and Urban Residence of Women}

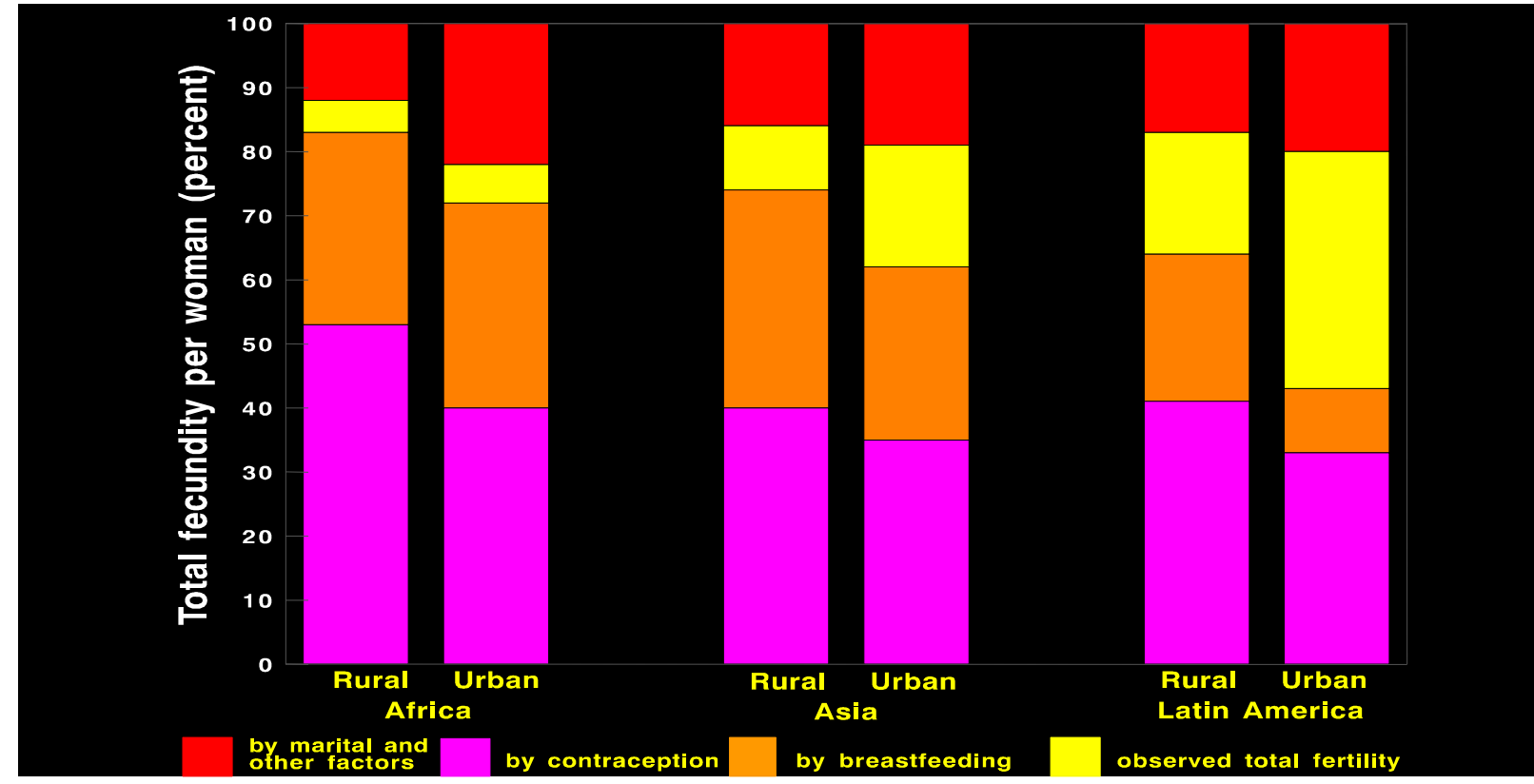

Source: World Fertility Survey data, courtesy of Dr. Shyam Thapa

Only in the urban areas of Latin America does contraception prevent more births than breastfeeding. That doesn't mean that breastfeeding is better than contraception as a way to regulate fertility. Obviously, the combined effects of both are needed. The point is that breastfeeding has a profound demographic effect. In order to prevent an increase in the 
population growth rate, it is essential that declines in breastfeeding be compensated by increases in contraceptive use.

The Biological Basis of Lactational Infertility

The second theme is that a biological basis exists for the fertility-reduction mechanism of lactation. A large number of studies have enabled a certain amount of understanding of the neuroendocrine cascade of events that causes lactational infertility.

To simplify what we know, suckling sends a neural impulse to the hypothalamus, which is interpreted as a signal to reduce the secretion of gonadotropin-releasing hormone $(\mathrm{GnRH})$, which, in turn, results in a lower amplitude and irregular frequency of the normally pulsatile secretion of luteinizing hormone (LH). In the absence of normal LH function, follicular development does not occur and there is no ovulation. Very often the first menstrual cycle during or after breastfeeding is not normal. Women often have their first menses before their first ovulation. Two factors help explain why women seldom get pregnant during lactational amenorrhea in the first six months postpartum: The earlier in the postpartum period that a woman experiences her first "menses," the less likely it is that ovulation occurred before that first bleeding episode. The earlier in the postpartum period that the first ovulation occurs, the less likely it is to be characterized by a luteal phase of adequate duration and progesterone production.

It is important to recognize that lactational infertility is a physiologic phenomenon. Given the same level of sexual activity, breastfeeding women are less likely than nonbreastfeeding women to become pregnant, and there is a biological explanation for that. Although it is accepted that there is a biological basis for lactational infertility, many aspects of the mechanism of action are not understood.

\section{Lactational Amenorrhea as a Contraceptive}

Breastfeeding is also used deliberately as a contraceptive. The Bellagio Consensus (Kennedy, et al., 1989) was an agreement, in 1988, on the part of some 20 scientists who had been studying the neuroendocrinology of lactational infertility in 13 studies in eight countries. They agreed that the risk of pregnancy is less than 2 percent in breastfeeding women:

\footnotetext{
* in the first six months postpartum,

* during full or nearly full breastfeeding, and
} 


\section{* during amenorrhea.}

All three of these conditions must exist.

In the studies that contributed to the consensus, breastfeeding, menses, and ovarian hormone levels were measured prospectively in lactating women, and either observed or estimated pregnancy rates were calculated. This natural contraceptive protection exists whether women know about it or not, and in these studies, women did not know about it. It is more useful if women know about it so they can, as individuals, use lactational amenorrhea as a contraceptive in a proactive way. If women can use these guidelines to increase their contraceptive benefits, this is the most convincing evidence of the validity of such natural contraception. Dr. Miriam Labbok and others (Pérez, et al., 1992) have done that; they have taught women a way to recognize when they are naturally infertile and when their fertility is returning. It is called the lactational amenorrhea method, or LAM. Dr. Alfredo Pérez, in the first empirical trial of LAM in some 400 women in Santiago, Chile, saw a pregnancy rate of 0.5 percent in the first six months postpartum during lactational amenorrhea, during full or nearly full breastfeeding in women who were using LAM as their contraceptive. Clearly, this rate compares with the rates of any other temporary, modern method of family planning in the first six months of use.

\section{Breastfeeding and Contraceptive Choice}

The fourth role of breastfeeding is that it affects the choice of a contraceptive. I have chosen just three examples of the way breastfeeding can affect contraceptive choice. Breastfeeding women should avoid the use of hormonal methods that contain estrogen because estrogen has been shown to decrease the woman's milk output. Especially during full or nearly full breastfeeding, breastfeeding women can have very thin, fragile vaginal epithelia and low levels of vaginal secretion during sexual relations. Accordingly, contraceptives that involve spermicide (which acts as a lubricant) can be very helpful then. Finally, postpartum IUD insertion during breastfeeding is associated with less pain and fewer removals for pain or for bleeding than IUD insertion at other times (Chi, et al., 1989). 


\section{Unchallenged Assumptions}

It is also important to question some of the assumptions about breastfeeding and postpartum contraception as Beverly Winikoff and Barbara Mensch (1991) have done in their recent paper on the postpartum period. I have divided the assumptions into three categories:

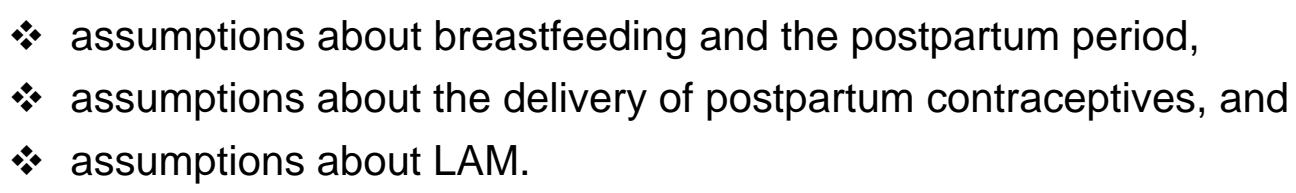

\section{Assumptions about Breastfeeding and the Postpartum Period}

Normal postpartum bleeding occurs only in the first two weeks after childbirth. This quotation about lochia (the menstrual-like discharge that is expelled as the uterine tissue breaks down, following childbirth) is from the most recent edition of Williams Obstetrics:

...when it persists for more than 2 weeks, however, it indicates either the retention of small portions of the placenta, or imperfect involution of the placental site or both. (p. 472)

Among the many studies of the return of fertility during breastfeeding, we have seen numerous patterns of postpartum bleeding through the sixth, seventh, and even eighth week postpartum. I've been told that this irregular bleeding occurs in breastfeeding women rather than in women who bottlefeed. What does it mean, especially in fully breastfeeding women? Does it signal early return of fertility? Is it imperfect involution, and if so, how common is it? (We have picked up cases of extended postpartum bleeding in nearly all of our samples, which generally contain only 25 women.) There is little research literature on the nature of postpartum bleeding patterns. This has obvious implications for the use of LAM. Perhaps more importantly, the early use of hormonal contraceptives might interfere with the normal postpartum bleeding process. Some providers start women on oral contraceptives before discharging them from the hospital after delivery.

The mother's milk supply is established by two weeks postpartum. We often hear that it is safe to start hormonal methods once the milk supply is established. Such advice reflects a lack of understanding of the milk supply. In a good breastfeeding relationship, the milk volume increases and plateaus many times, with each growth spurt of the child. The baby is 
not satisfied with the current volume, and fusses, so the mother puts the baby to the breast more frequently and this extra nipple stimulation results in greater prolactin production and increased milk. The milk supply is probably fully established at about six months postpartum.

Lactational abstinence is practiced. Coital initiation and frequency after childbirth are probably somewhat subject to local norms. The breastfeeding women in some of our studies kept coital logs. Despite inherent limitations of self-reporting, there is evidence of sexual activity. Whenever I mention postpartum or lactational abstinence to clinicians in the field, they get almost hostile and insist that abstinence is ancient history. Sexual behavior during breastfeeding should be studied more closely. We could find, for example, that postpartum sexual debut occurs early but that frequency is low, so there is decreased exposure to pregnancy. Or, we may find frequent intercourse if couples believe they will not become pregnant.

\section{Assumptions about Postpartum Contraception Delivery}

Women are highly motivated to practice contraception immediately postpartum. We simply need some data on this point. This assumption makes some sense, but it may be too simple a view of the motivation to practice contraception. Women have lots of other things on their minds after giving birth. This is not a criticism of effective programs that provide postpartum family planning. It is a question regarding the millions of women who do not deliver in hospitals and who do not practice contraception in the postpartum period. Why do they not practice contraception? We need to ask.

You must give a contraceptive immediately postpartum or you'll never see the woman again (until her next delivery). If a woman doesn't obtain a method immediately postpartum, does she want one?

\section{Assumptions about LAM}

LAM will be ineffective because women will get pregnant as soon as their natural protection expires, because they will not have started a second method. One could propose a counterassumption: if women are provided with their second method or a back-up method at the time they learn LAM, then not only will there be no gap in contraception, but their total 
contraceptive continuation rates will be better than if they hadn't used LAM. Neither the assumption nor the counter-assumption is supported by any data.

LAM is too difficult for women to understand and use correctly. Some argue that the three conditions of the Bellagio Consensus are hard to comprehend. In Pakistan and the Philippines, we turned the guidelines into a jingle, and women don't seem to have any problem with them. Perhaps we are making the concept difficult when it isn't. Once again, empirical data are needed on this point.

\section{Integration of Breastfeeding into Birth-spacing \\ Strategies: The Recife, Brazil Study \\ based on a presentation by Vilneide Braga Serva}

The Instituto Materno Infantil de Pernambuco (IMIP) is studying the effects of introducing the lactational amenorrhea method (LAM) as a postpartum family planning strategy. Because the data are still being collected, this discussion focuses on characteristics of the hospital, on the study's objectives and design, and on the characteristics of the women included in the study.

\section{Instituto Materno Infantil de Pernambuco}

IMIP is a mother and child health (MCH) hospital, founded in 1960 and located in Recife, the capital of the northeastern State of Pernambuco. The semi-arid northeast is the poorest region in Brazil and has the worst health data in the country.

Approximately 3,800 births occur at IMIP each year. As IMIP is a referral hospital, 40 percent of these births involve high-risk pregnancies, 30 percent of the deliveries are by caesarean section, and 15 percent of the babies are of low birthweight. The outpatient clinics attend about 300,000 patients a year. A community outreach program, begun in 1983, covers six districts. In addition, IMIP is involved in teaching and research.

\section{Breastfeeding Promotion}

Not only are breastfeeding rates low in Brazil, but health practitioners and clients often see breastfeeding as an obstacle to family planning; some women actually stop breastfeeding because they want to initiate contraception. These attitudes are part of the context in which the project was undertaken. After the national breastfeeding program was initiated, the mean 
duration of breastfeeding increased from 99 days in 1981 to 134 days in 1989. Breastfeeding rates at IMIP have always compared favorably with the national figures, although much remains to be done. In 1990, for example, at 40 days postpartum, 98 percent of the women were breastfeeding and 75 percent were breastfeeding exclusively, and at three months, nearly 23 percent of the women were breastfeeding exclusively.

Despite the high rates of caesarean sections and of low-birthweight babies, about 96 percent of the mothers are exclusively breastfeeding at discharge. The hospital's long history of encouraging breastfeeding goes back to its founder, Professor Fernando Figueira, who in 1974, as Secretary of Health of Pernambuco, prohibited distribution of powdered milk and bottles to women in maternity units. In 1987, as part of the national program to encourage breastfeeding, IMIP established its breastfeeding incentive center/breast-milk bank. In 1992, IMIP became Brazil's first "baby-friendly" hospital, after strict evaluations by UNICEF, the Pan American Health Organization (PAHO), the Ministry of Health, and other institutions. It thus follows the "ten steps to successful breastfeeding." Accordingly, measures taken at IMIP to promote breastfeeding include the following: written materials are produced and provided; all workers are trained about breastfeeding — cafeteria workers and porters as well as health-care providers; breastfeeding is discussed with clients during prenatal care, which also includes provision of family planning information; mothers and babies are kept together after the delivery, and mothers are helped to begin breastfeeding within a half-hour in normal deliveries and caesarean sections; there is total rooming-in; if babies are very premature or sick, their mothers are taught how to express milk and maintain lactation; bottles and pacifiers are never used-if necessary, babies are fed by syringe. In addition, through groups and meetings organized and run by the mothers themselves, breastfeeding monitors-mothers trained and supported by IMIP staff-continue to promote breastfeeding when the women have left the hospital.

\section{The Research Project}

The project is designed to assess the feasibility and effects of LAM. It will compare two groups, each consisting of 350 mothers who delivered at IMIP and their babies, at the end of the first year postpartum. The groups are similar, but one predates the introduction of LAM and thus provides baseline data, whereas the other follows the intervention and thus reflects its effects. The specific objectives of the project are to ascertain the proportion of women who accept LAM as a method, to compare the two groups in the first postpartum year with regard to: 
exclusive and total breastfeeding rates;

use of contraceptive methods;

proportion of women who become pregnant;

* health and development of the infants;

health of the women; and

sexual activity of the women.

Moreover, the women's satisfaction with the service will be assessed, as well as the per-user costs, comparing the two groups studied. Prior to intervention, IMIP had been offering IUDs, oral hormonal contraceptives (progesterone-only pills), condoms, and diaphragms as postpartum family planning methods.

The intervention itself consisted of introducing LAM at IMIP and convincing health professionals of its viability; training health professionals; individually

counseling mothers on postpartum family planning methods, including LAM; and promoting LAM through leaflets, telephone consultations, and letters. The mothers' acceptance of each method is shown in Table 4.1.

\begin{tabular}{lr}
\hline Method & Percent \\
\hline IUD & 16.5 \\
Orals & 60.0 \\
Condom & 10.7 \\
Diaphragm & 1.0 \\
Tubal ligation & 3.6 \\
Injectables & 1.9 \\
LAM & 3.9 \\
Spermicide & 0.9 \\
Calendar/rhythm method & 1.6 \\
\hline
\end{tabular}

Table 4.1 Mothers' Acceptance Rate of Contraceptive Methods

\section{Findings}

This discussion, which reports on preliminary findings, covers primarily the women in group $A$, the group studied prior to the intervention. Data on the women in group $B$, the group established after the intervention, are still being collected and analyzed; any data given here are preliminary.

A majority of the women were in their twenties, with 37 percent between 20 and 24 years of age. Nearly all had had at least some schooling. Only 50 percent were married, but another 41 percent were living with their partners. At the time of the interview, the mean number of gestations was 2.3, and the mean number of live births was 1.8.

With regard to breastfeeding, 88 percent of the women had breastfed their previous 
child and nearly 99 percent breastfed their current infant. The mean duration of breastfeeding for the current infant was four months. At the end of the first year postpartum, 49 women (14 percent) had become pregnant again; 16 of these women had had an abortion.

Although the data for group B are only now being analyzed, it is known that 71 (20 percent) of the 350 women chose LAM as a postpartum family planning method. Preliminary findings show that among women in this group, the mean duration of breastfeeding for the current infant appears to be higher. Of the 252 women in group B who were observed at six months postpartum, only 2.8 percent had become pregnant by that time.

\section{The Ecuador Experience in Using the Lactational Amenorrhea Method for Birth-spacing}

summary of a presentation by Virginia H. Laukaran

The Institute for Reproductive Health is part of the Department of Obstetrics and Gynecology in the medical school at Georgetown University in Washington, D.C. Its work is supported by the U.S. Agency for International Development, and its mandate is to provide research and technical assistance for "natural" family planning methods and the fertility aspects of breastfeeding. In 1988-90, the Institute undertook a pilot study in Ecuador to determine the feasibility of incorporating the lactational amenorrhea method (LAM) into a broad-based family planning program. This introduction of LAM was conducted in collaboration with Centro Medico de Planificacion Familiar (CEMOPLAF) (Wade, et al. 1992), a private family planning service delivery program in Ecuador, and the Los Angeles Regional Family Planning Council.

\section{The Study}

In the Ecuadoran pilot study, LAM was introduced to postpartum clients in four CEMOPLAF clinics alongside a full range of family planning methods, including the pill, IUD, and barrier methods. Clients who wanted an early IUD insertion were not encouraged to adopt LAM. CEMOPLAF was motivated to introduce LAM in order to add a new service that would benefit mothers and children and as a step in its expansion from a family planning program to a program providing a full range of prenatal, interim, and postpartum services. 
As shown in Table 4.2, together the four clinics saw 2,905 new clients during the period of the study, of whom 431 (15 percent) were LAM-eligible (i.e., postpartum, amenorrheic, and fully breastfeeding). Of this target population of eligible clients, 133 (31 percent) accepted LAM.

\begin{tabular}{|c|c|c|c|c|c|c|c|}
\hline \multirow[b]{3}{*}{ Clinic } & \multicolumn{5}{|c|}{$\begin{array}{c}\text { Table } 4.2 \\
\text { Utilization of LAM, CEMOPLAF, } 1991\end{array}$} & & \\
\hline & $\begin{array}{c}\text { All } \\
\text { new }\end{array}$ & & $\begin{array}{l}\text { LAM- } \\
\text { eligible }\end{array}$ & & $\begin{array}{l}\text { LAM } \\
\text { ceptors }\end{array}$ & & \\
\hline & $\mathbf{N}$ & $\%$ & $\mathbf{N}$ & $\begin{array}{l}\% \text { of all } \\
\text { new } \\
\text { clients }\end{array}$ & $\mathbf{N}$ & $\begin{array}{c}\% \text { of } \\
\text { LAM- } \\
\text { eligible }\end{array}$ & $\begin{array}{c}\% \text { of } \\
\text { all } \\
\text { new } \\
\text { clients }\end{array}$ \\
\hline Quito & 731 & 100 & 117 & 16 & 9 & 8 & 1 \\
\hline $\begin{array}{l}\text { Santo } \\
\text { Domingo }\end{array}$ & 1,123 & 100 & 163 & 15 & 48 & 29 & 4 \\
\hline Latacunga & 625 & 100 & 69 & 11 & 48 & 70 & 8 \\
\hline Cajabamba & 426 & 100 & 82 & 19 & 28 & 34 & 7 \\
\hline Total & 2,905 & 100 & 431 & 15 & 133 & 31 & 5 \\
\hline
\end{tabular}

In subsequent interviews, 77 percent of the LAM users said they had been satisfied with the method, and the mean duration of use was 3.5 months. Sixty-two percent of the users adopted a continuation method. Seventy-three percent of the LAM acceptors were first-time users of any contraceptive method. One problem noted was that the clinic's service fee proved an obstacle to the use of LAM by low-income, indigenous women who expected to receive a commodity if they paid a fee.

Based on this successful pilot program, CEMOPLAF decided to go to a full-scale introduction of LAM in all 22 of its clinics. It also developed a strategy to meet the needs of indigenous clients through existing community-based promoters. Operations research objectives for this second phase include demonstrating the feasibility of LAM in a communitybased program, evaluating the influence of LAM on cost-per-user basis, and determining, 
with this larger sample, the acceptance of continuation methods and the birth intervals for LAM users. Continuation among LAM users will be compared with other postpartum users stratified by prior contraceptive use. The Institute is also in the process of developing LAM pilot projects in Haiti, Bolivia, Yemen, and several African countries.

\section{Priorities for LAM Research}

Among the priority subjects for postpartum family planning research identified by Winikoff and Mensch (1991) were several questions related to LAM:

1. Can providers learn LAM?

2. Can providers be successful in educating women?

3. Can women understand and use the information?

The Ecuadoran pilot study suggests a strong affirmative answer to each of these three questions. Nevertheless, several breastfeeding initiatives discussed at this conference have reported problems in incorporating LAM into postpartum services. Difficulties in introducing a new contraceptive are to be anticipated, and careful planning is required for any such introduction. The contraceptive introduction process is discussed in some detail by Williamson, et al. (1991). The authors point out that "contraceptive introduction can be a long and complex process, involving such components as consensus building among donors, policy makers, program managers, and providers" (235). NORPLANT ${ }^{\circledR}$ introduction efforts, begun in 1979, are an example of the slow process of contraceptive introduction. Sally Tom's presentation pointed to another factor in the acceptance of LAM. The method is "dissonant" with the usual medical model of contraception because no medical procedure or prescription is involved. The method is client-controlled and information-based and it involves empowerment through information. Furthermore, the method is also "dissonant" with respect to the demographic paradigm. It is often not considered a "modern" method and has aroused some suspicion based on this lack of "fit" with the accepted paradigms.

In practice, success in introducing LAM can be expected to vary depending on how closely programs adhere to the established medical model. CEMOPLAF's strong user orientation and support for integrating health care and family planning provided a favorable setting for an initial LAM introduction. In any case, a new contraceptive can only be successful if management provides adequate support.

Some key questions for LAM operations research remain to be answered and are priority research topics for the institute. 
1. Does LAM increase the acceptance of other methods? If yes, under what circumstances will acceptance increase?

2. Will LAM users return for a continuation method?

3. In what types of programs can LAM be incorporated effectively?

4. What level of provider support is needed for effective LAM use?

5. How do community-based and clinic-based LAM services compare with one another?

Outcome-oriented LAM research is also needed to compare outcomes in LAM programs with traditional postpartum approaches. Ultimately, longer-term research to determine the impact of LAM on birth intervals is needed.

Another research area of high priority is designed to improve LAM. Crucial questions in this area include the following:

1. How much breastfeeding is sufficient to maintain lactational amenorrhea?

2. What specific breastfeeding practices really make a difference in lactational amenorrhea?

3. Do liquid and solid supplements have differential effects on the resumption of menses, nutrition, and the health of infants?

4. What factors predict the early return of menses?

5. Can LAM be extended, in some populations, beyond six months?

Winikoff and Mensch (1991) also called for research designed to test the two assumptions of the immediate postpartum family planning model-that is, that women are most receptive to family planning at the time of childbirth and that they will not generally return for services. Field studies of this kind would provide a better understanding of the postpartum context for LAM. The research agenda laid out here reveals the prodigious task inherent in the introduction of this new method. The beneficiaries of this effort will be women who wish to postpone hormonal contraception during the immediate postpartum period and those who do not choose an IUD. New users who have no experience with contraception may also receive special benefits from the method. In addition, and not to be taken lightly, infants will receive the benefits of optimal nutrition and immunological protection from 
exclusive breastfeeding. Programs will benefit by increasing the range of methods available for lactating women. 


\section{CHAPTER 5 \\ CONTRACEPTIVE METHODS AND BIRTH-PLANNING STRATEGIES \\ Juan Diaz, Chair}

\section{Postpartum IUDS: Challenges and Possibilities}

based on a presentation by Amy Pollack

IUDs are a very common method of contraception in the developing world. Although the Association for Voluntary Surgical Contraception (AVSC) is generally known for its work with sterilization, in the late 1980s it decided, for ethical reasons and reasons of demand, to consider support for programs that wanted to start offering postpartum IUDs. Certain questions arose about the use of postpartum, or even interval, IUDs in low-resource settings. Indeed, as with any method, postpartum IUDs require that program managers look at the entire system - at the medical and programmatic issues and at the need, which interact with one another. If the need is great enough, a program may be viable even if it fails to adequately address certain issues in a traditional way. Each of these three componentsmedical issues, programmatic issues, and need-are discussed below with regard to postpartum IUDs. The presentation concludes with data from a case study.

\section{Postpartum IUDs}

The World Health Organization has defined four types of IUD insertions, based on the timing of the insertion. Postplacental insertion occurs in the delivery room immediately after expulsion of the placenta. Immediate postpartum insertion occurs before hospital discharge, preferably within 48 hours of delivery, although insertion within the first week is possible if the woman has an extended hospital stay. Both of these types are considered postpartum IUDs. Delayed insertion occurs one to six weeks after delivery, although it is not recommended because of increased risk of perforation, as the uterus is still soft. An interval insertion, by definition, is done at a follow-up examination at least six weeks after delivery.

\section{Medical Issues}

Among the main medical concerns associated with postpartum IUD service delivery are sexually transmitted infection (STI) prevalence, screening capacity, and aseptic technique.

Information on STI prevalence is often lacking in low-resource settings. Often only 
gross estimates are possible, although the HIV epidemic has yielded some information on HIV prevalence, which may serve as an indicator for the risk of STIs in general.

Not surprisingly, low-resource settings also lack laboratory screening capacity. To complicate matters, it is more difficult to diagnose STIs based on the signs of infection during pregnancy and postnatally than when examining women at times that are not associated with pregnancy.

Aseptic technique is a concern with postplacental insertions. In low-resource settings, incidence of infection and risk of maternal mortality can be high not only following caesarean sections but also following vaginal delivery. Introducing IUDs, especially if aseptic technique is poor, may be an added risk factor.

Other method-specific medical concerns include expulsion rates, perforations, and missing strings. High expulsion rates can result when operators are inexperienced, but they decrease with good training in fundal placement. The perforation rate does not appear to be high for post-placental or immediate postpartum insertion; the incidence of missing strings appears to be quite high at the six-week visit, but decreases over time. Good data are not available regarding service delivery implications of increased numbers of clients with missing strings over the long term.

\section{Programmatic Issues}

The most important programmatic concern is to ensure voluntarism. In the delivery room setting, it would be easy to perform an IUD insertion without the woman's knowledge or full consent. Probably the only way to deal with voluntarism in this setting is to take it into account on initiating a program and to overcompensate for a possible lack of informed consent at every relevant juncture.

A second programmatic issue is linkage of services. Some system for linkage is needed when different services are involved. Ideally, a woman who is getting a postpartum IUD will receive counseling in prenatal care, be given a card or other record to take with her when she goes to the hospital to deliver, be recounseled on leaving the hospital, and be given a card to take with her when she goes for family planning care. The card reinforces the information the woman gives to providers.

Other issues relate to cost-effectiveness, including the cost of double protection and training costs. It is often thought that the addition of a postpartum IUD program is highly costeffective because the infrastructure is already in place. Yet, personnel have to be trained to use the technology and to provide counseling; this is an ongoing cost and must be 
considered up front to assure reliable and high-quality program continuity.

\section{Assessing Need}

Medical risks and programmatic risks must be weighed against need. Need can be assessed by looking at fecundity and access to services. Fecundity depends on length of breastfeeding in the population and on practices and traditions for not having intercourse. Women in programs with which AVSC has been associated say that, despite a 40-day abstinence period, they want an immediate postpartum method because intercourse might not be avoidable. The issue of access to services works both for and against postpartum IUDs. Difficult access argues for an immediate postpartum IUD so an unintended pregnancy can be avoided, but, on the other hand, a woman with an IUD ought to be able to get adequate follow-up care for any related problems. (It should be noted that it is generally easier to remove an IUD than to put one in!)

\section{Nyeri, Kenya}

AVSC is involved in a postpartum IUD program in a hospital in Nyeri, Kenya. This site was started as a pilot study site. About 80 percent of the women breastfeed, and access to contraceptive services is poor to moderate.

The setting is problematic in many ways. Kenya, in general, has very high rates of infertility due to sexually transmitted diseases (STDs) or pelvic infections, and of infants with chlamydial or gonococcal eye infections or chlamydial pneumonia (indicators for maternal infection). Kenya itself is characterized by a total fertility rate of 6.8 , a maternal mortality rate of greater than $300 / 100,000$, and an infant mortality rate of 70/1,000; Nyeri-specific rates are not available, but are probably slightly better than average for Kenya. There are 600-700 deliveries per month at the hospital in Nyeri.

The situation is exacerbated by a lack of laboratory screening capacity. On the other hand, the staff is committed to following good infection prevention practices during delivery; voluntarism is good; linkage systems are in place and achieved by cards given to women during prenatal care; and all of the midwives are trained in counseling about postpartum IUD placement and follow-up on site. There is an ultrasound on site to verify missing IUD/missing strings only.

The results with the AVSC program have been good and have improved over the two years in which the program has been in existence. There is a 62 percent follow-up rate, and infection and expulsion rates appear to be low (about 5 expulsions in 300). Demand has 
been higher than can be met due to commodities limitations.

Based on the positive outcome of this small project, postpartum IUDs are now offered on a regular basis at this hospital as part of a postpartum contraception initiative. The increasing client demand probably indicates user satisfaction. If that continues, the demand to extend services to other existing delivery sites will occur. It is AVSC's sense that if expansion is slow, with concentration on establishing service delivery linkages between hospitals and existing family planning care, and effort is concentrated on training and followup, medical barriers to postpartum IUD services may be overcome, even in low resource settings.

\section{Use of Hormonal Methods in the Postpartum Period}

based on a presentation by Marcia Angle

This presentation about the use of hormonal methods in the postpartum period covers four main issues: the goal of postpartum family planning services, pharmacologic considerations, programmatic considerations, and additional reproductive health considerations.

Pharmacologic considerations in the use of hormonal methods include effects on breast milk, effects on the breastfed infant (neonatal liver, developing brain), and effects on maternal coagulation and other parameters. Programmatic considerations include the effect of the timing and location of family planning services on women's choices of postpartum methods (i.e., what kinds of postpartum services do women actually want?); the lactational amenorrhea method (LAM) and the "double protection dilemma"; and some common guidelines for initiating postpartum hormonal contraception. The additional reproductive health considerations to be addressed are the advantages and disadvantages of hormonal contraceptives to reproductive health; disadvantages may include the lack of significant protection against sexually transmitted disease (STD) and reproductive tract infection (RTI), and possible decreased concomitant condom use (due to the high contraceptive efficacy of hormonal methods).

\section{Basic Goals of Postpartum Family Planning Services}

The basic goals of postpartum family planning services include improving infant health and improving maternal health. Improvements in infant health can be achieved by promoting breastfeeding and encouraging delay of the next birth. Maternal health is also improved by 
promotion of breastfeeding, through more rapid uterine involution, facilitation of maternal/infant bonding, and improved triglycerides and glucose tolerance. Encouraging delay of the next conception prevents maternal depletion syndrome. Furthermore, by helping the mother avoid RTIs and STDs, the consequent risks of morbidity and mortality are reduced.

\section{Pharmacologic Considerations}

There are three pharmacologic considerations for breastfeeding mothers.

First, estrogens decrease milk volume. Combined oral contraceptives (COCs) cause a significant decrease in milk output and total energy content (as well as widespread changes in milk constituents) (WHO, 1988) and cause alterations of milk quality.

Second, is the human neonatal liver capable of handling the excess steroid burden of estrogens and progestins received through breast milk? Estrogens tax hepatic function significantly more than do progestins.

Third, is human neonatal brain development susceptible to influences of exogenous sex steroids? Speculation on this possibility has raised important concerns (Harlap, 1987). There are marked normal fluctuations of human testosterone and estradiol in the first months of neonatal life: testosterone reaches a minimum at one week of age, then rises and peaks at about two months; estradiol rises in the first few weeks of life and then falls to childhood levels by three to four months. Rodent experiments are models suggestive of a period of hormonal imprinting in the first few postnatal weeks, with consequent behavioral effects from postpartum hormonal exposure: exposing newborn female rodents to exogenous testosterone leads to more masculine behavioral traits in later life (mounting); exposing newborn male rodents to estradiol leads to more receptive mating postures in later life. Human data, however, are very reassuring: long-term follow up of infants whose mothers used DMPA while breastfeeding revealed no developmental delay or other adverse effect, and there is no demonstrable teratogenicity from current, lower-dose contraceptives.

There are other pharmacologic considerations regarding the use of hormonal contraceptives for postpartum women: peripartum hypercoagulability (known to be present for the first few weeks postpartum) is likely to be exacerbated by exogenous estrogens; recommending a three-week delay in initiating COCs (for nonbreastfeeding mothers) is typical. When begun six weeks postpartum, the progesterone vaginal ring (Diaz, et al., 1991) and NORPLANT ${ }^{\circledR}$ (Diaz, et al., 1985) delay onset of first menses. In contrast, anecdotal evidence suggests that immediate postpartum use of DMPA may prolong and increase 
postpartum bleeding (American Health Consultants, 1993).

\section{Programmatic Considerations}

Availability of services affects the postpartum woman's choice of contraceptive methods. One must bear these service realities in mind when considering when to recommend initiation of (or distribution of) hormonal contraceptives. (See Table 5.1.)

\section{Table 5.1}

\section{Timing and Location of FP Services for New Mothers: A Continuum of Opportunities}

\begin{tabular}{|c|c|c|}
\hline Most complete & Typical & Most challenging \\
\hline $\begin{array}{l}\text { Antenatal care coordinated with } \\
\text { peripartum and postpartum care }\end{array}$ & $\begin{array}{l}\text { Antenatal care, without } \\
\text { coordination with } \\
\text { peripartum services }\end{array}$ & No antenatal care \\
\hline $\begin{array}{l}\text { Peripartum care with VSC, } \\
\text { postpartum IUD, and NORPLANT }{ }^{\circledR} \\
\text { available }\end{array}$ & $\begin{array}{l}\text { Peripartum care with } \\
\text { limited range of methods }\end{array}$ & $\begin{array}{l}\text { Delivery by TBA } \\
\text { (with or without } \\
\text { training) }\end{array}$ \\
\hline $\begin{array}{l}\text { Routine ( } 4 \text { to } 6 \text { weeks) postpartum } \\
\text { care with VSC, postpartum IUD, and } \\
\text { NORPLANT }{ }^{\circledR} \text { available }\end{array}$ & $\begin{array}{l}\text { No routine postpartum } \\
\text { care }\end{array}$ & No postpartum care \\
\hline
\end{tabular}

Note: $\mathrm{VSC}=$ voluntary surgical contraception; TBA=trained birth attendant.

The other major issue we need to keep in mind concerning when to recommend initiation of hormonal contraceptives is lactational amenorrhea and the "double protection dilemma." What is the optimal timing for initiation of a hormonal family planning method? Immediately postpartum? Four to six weeks? With initiation of supplements? With return of menses if before six months? With return of menses, whenever it happens? At six (?) months, regardless of return of menses? (See Table 5.2.)

What is the degree to which lactational amenorrhea should be relied upon as evidence that a woman is not pregnant? For example, does a four-month or eight-month postpartum, amenorrheic, breastfeeding mother need a pregnancy test to begin a progestin-only method?

How important is the inconsistency between the health provider's message about use of hormonal contraceptives during the breastfeeding period and cultural taboos for a breastfeeding woman against sexual intercourse? 
Table 5.2

Initiation of Postpartum Hormonal Contraceptives: Some Common Guidelines

\begin{tabular}{||l|l||}
\hline \multicolumn{1}{|c|}{ Fully or nearly full breastfeeding } & \multicolumn{1}{c||}{ Not breastfeeding } \\
\hline \hline $\begin{array}{l}\text { Avoid estrogen until there is only "token" } \\
\text { breastfeeding, unless no other effective } \\
\text { family planning method is acceptable to } \\
\text { the woman. }\end{array}$ & $\begin{array}{l}\text { Begin estrogen-containing OCs two weeks } \\
\text { postpartum. }\end{array}$ \\
\hline $\begin{array}{l}\text { Begin NORPLANT } \\
\text { discharge if option of insertion at 4-6 } \\
\text { weeks postpartum is not possible (see } \\
\text { pharmacologic considerations). }\end{array}$ & $\begin{array}{l}\text { Begin NORPLANT } \\
\text { if available. (NORPLANT } \\
\text { be able to return to clinic site for management discharge, } \\
\text { of side effects and NORPLANT }{ }^{\circledR} \text { removal.) }\end{array}$ \\
\hline $\begin{array}{l}\text { Begin injectables at 4-6 weeks } \\
\text { postpartum. }\end{array}$ & $\begin{array}{l}\text { Either begin injectables before hospital } \\
\text { discharge or wait until 4-6 weeks postpartum, } \\
\text { since the woman must be able to make routine } \\
\text { clinic follow-up visits. }\end{array}$ \\
\hline $\begin{array}{l}\text { Begin progestin-only pills (POPs) at 4-6 } \\
\text { weeks postpartum. }\end{array}$ & $\begin{array}{l}\text { Begin POPs within 4-6 weeks, if it is desired } \\
\text { method (can distribute antenatally or at the } \\
\text { hospital). }\end{array}$ \\
\hline \hline
\end{tabular}

Note: These guidelines are in use without the benefit of input concerning what women want, but are defensible in terms of the pharmacoloaic effects.

\section{Additional Reproductive Health Considerations}

Table 5.3.

Different hormonal methods vary in their reproductive health benefits, as shown in

Hormonal contraceptives have two important reproductive health disadvantages: first, their failure to provide significant protection against STDs and RTIs, and second, the possibility that using an effective family planning method may decrease the motivation to use barrier methods for STD protection. Sexually transmitted diseases include human immunedeficiency virus (HIV), pelvic inflammatory disease (PID) (chlamydia, gonococcus, other STD), genital ulcer disease (GUD) (causes of GUD are, chiefly, syphilis, chancroid, and herpes), human papilloma virus (HPV) and consequent cervical cancer, Hepatitis B virus (HBV), and others (including trichomoniasis). Other RTIs include PID from non-STD sources (hormonal contraceptives do protect against postpartum, postabortal, and post-IUD endometritis), vaginitis (anaerobic and yeast), and infection of traumatized tissue. 


\begin{tabular}{|c|c|c|c|c|}
\hline \multicolumn{5}{|c|}{$\begin{array}{l}\text { Table } 5.3 \\
\text { Reproductive Health Advantages of Hormonal Contraceptives for Postpartum Women }\end{array}$} \\
\hline \multirow[t]{2}{*}{ Advantages } & \multicolumn{4}{|c|}{ Method } \\
\hline & POPs & NORPLANT® & Injectables & cocs \\
\hline Minimal effects on breastfeeding & + & + & + & 0 \\
\hline High-use effectiveness for postpartum women & + & +++ & +++ & ++ \\
\hline Can be dispensed antenatally & + & 0 & 0 & + \\
\hline Prompt reversibility & ++ & + & 0 & ++ \\
\hline Menstrual cycle regularity & 0 & 0 & 0 & + \\
\hline $\begin{array}{l}\text { Decreased menstrual cramping, blood loss, } \\
\text { and anemia }\end{array}$ & + & ++ & + & ++ \\
\hline Decreased ectopics & + & + & ++ & +++ \\
\hline Decreased endometrial cancer & ++ & ++ & ++ & ++ \\
\hline Decreased ovarian cysts and ovarian cancer & 0 & 0 & 0 & ++ \\
\hline $\begin{array}{l}\text { Decreased risk of ascent of endocervical } \\
\text { gonococcal infection }\end{array}$ & $?+$ & $?+$ & + & + \\
\hline
\end{tabular}

\section{Some Urgent Research Questions}

The following research questions address a few of the relevant issues in the use of hormonal contraceptives during the postpartum period.

1. In order to maximize efficacy but minimize the "double protection dilemma," when should lactating women begin their progestin-only method?

2. What instructions to mothers can be clearly understood, remembered, and followed concerning method initiation?

3. Are there any adverse maternal or infant consequences to initiating NORPLANT ${ }^{\circledR}$ immediately postpartum?

4. If providing an effective contraceptive decreases women's motivation to (or leverage for persuading men to) use condoms, how can motivation to use condoms for STD protection be increased? 
5. To what degree is the acceptance of hormonal contraceptives or condoms impeded by the inconsistency between the health provider's message about use of hormonal contraceptives during the breastfeeding period and cultural taboos for breastfeeding women against sexual intercourse?

\section{The Role of Barrier Methods in the Postpartum Period}

based on a presentation by Pat Semeraro

Barrier methods, which once played a major role in family planning programs, fell into relative disuse with the advent of noncoital methods such as oral contraceptives (OCs) and IUDs. However, they are currently receiving renewed attention, especially in view of the HIV epidemic and the rapid growth of sexually transmitted diseases (STDs).

\section{Barrier Methods and Sexually Transmitted Disease}

Barrier methods today are the best defense against STDs and the associated infertility, morbidity, and mortality. During postpartum abstinence, barrier methods might be especially important, if the male partner seeks sexual satisfaction elsewhere and as a result increases the woman's risk of contracting an STD.

The effectiveness of barrier contraceptives in protecting against STDs is indicated by a study in the American Journal of Public Health (Rosenberg, et al., 1992). Compared with women who used no contraceptives, women who used the sponge had reductions of 71,74 , and 13 percent in gonorrhea, trichomonas vaginalis, and chlamydia, respectively, while women who used the diaphragm had corresponding reductions of 65,71 , and 72 percent.

Significantly, women whose partners used condoms had much smaller decreases-34 percent for gonorrhea, 30 percent for trichomonas, and 3 percent for chlamydia. This difference in effectiveness possibly reflects less consistent condom use as a result of male resistance. It suggests that, whereas STD prevention efforts have focused almost exclusively on condoms, there is a need to identify and stress woman-controlled methods-methods women can use independently of their male partners. That is not to say that women must take complete responsibility for STD prevention. Men must still be educated about their role in transmitting diseases, and women must still be empowered to negotiate condom use with their partners.

\section{Barrier methods in a postpartum method mix}

The potential importance of barrier methods in postpartum family planning programs 
stems not only from the protection they offer against STDs but also from the fact that most can be used as soon as sexual relations are resumed and that none affects breastfeeding. Barrier methods become important if we adopt a postpartum strategy based on the concept of a method mix - that is, use different methods to meet the different needs of women during different stages of the postpartum period. They can, for example, be used as a temporary method by women who will later use oral contraceptives or an IUD. As part of a postpartum method mix, barrier methods have two main uses:

1. They provide early contraceptive protection to those at risk of early fertility return, such as nonbreastfeeding women and women who breastfeed less than fully.

2. They provide additional protection later in the postpartum period to those using the lactational amenorrhea method (LAM) at a time when there is a higher risk of fertility return-that is, around the sixth month postpartum.

Those uses are, of course, in addition to their use as a primary method.

\section{Condoms and spermicides}

Although condoms and spermicides tend to be used less effectively than other contraceptives, they are still a viable option for many postpartum women. Moreover, if a woman is nursing, the contraceptive effects of breastfeeding can combine with those of condom use.

The use of condoms and spermicides during the postpartum period has several advantages. Like other barrier methods, they do not affect breastfeeding. Spermicides may alleviate the vaginal dryness common in lactating women during intercourse. Finally, supplies of condoms and spermicides can be provided at delivery, to be used when needed.

However, condoms are not readily available in all parts of the world. In addition, as mentioned, problems of acceptability and, hence, use can also be a disadvantage.

"Female condoms," a recently developed alternative to the male condom, might alleviate this problem to some extent, as they are controlled by the woman and can be inserted in advance of intercourse. A major disadvantage, however, is cost, which in the United States is $\$ 2.25$ per condom. Heavily subsidized social marketing and distribution systems would be needed in order for this method to reach significant numbers of women in developing countries. 


\section{Diaphragms, caps, and sponges}

Diaphragms and cervical caps are not advisable for immediate postpartum use: they cannot be fitted until the genital tract returns to its normal shape, which is usually four to six weeks after delivery, and they need to be refitted once the woman loses five to ten pounds. Contraceptive sponges, in contrast, can be used at any time. They might also have the advantage of greater acceptability than some other barrier methods.

\section{Conclusion}

Barrier methods of contraception seem to be making a comeback, and their use should be promoted. They are reasonably effective, acceptable, and safe methods, and they have some particular advantages for use in the postpartum period.

There is a general need to widen the choice of methods that act as contraceptives and as prophylactics against STDs. Female-controlled methods, in particular, need to be given more attention both in STD-reduction programs and postpartum family planning programs.

\section{Introduction of the Minipill in Mexico}

based on a presentation prepared by Aurora Rabago, Doroteo Mendoza, and Kathryn Tolbert

The Mexican Social Security Institute (IMSS), through its postpartum program, has had great success in promoting birth-spacing to women. Approximately 70 percent of the women who give birth in IMSS hospitals leave with a temporary contraceptive method or, for those who wish to have no more children, a tubal ligation. The IUD and tubal ligation were, until September 1989, the methods offered for immediate postpartum contraception. ${ }^{2}$ At that time, the "minipill"—or progestin-only pill—was introduced as an additional early postpartum option consistent with breastfeeding. A package of pills was given to the mother in the hospital, to be started one week after the birth of the baby. Subsequent supplies were to be obtained at the woman's regular IMSS medical unit.

\section{Study Background}

At the beginning of 1991, the Population Council and IMSS began a baseline study to

\footnotetext{
${ }^{2}$ Hormonal methods, pills, and injectables, are available after the first postpartum visit, depending on the health and breastfeeding status of the woman.
} 
examine the effect of introducing the minipill on breastfeeding patterns in the IMSS postpartum population. A cohort of women who accepted immediate postpartum IUDs were followed as a comparison group. Two sites, Querétaro and Yucatán, were chosen for the work. The baseline study focused on method acceptance and use, method continuity, breastfeeding duration and characteristics (exclusive, nonexclusive), factors influencing breastfeeding, and sociodemographic characteristics of the mothers.

The result of introducing the minipill was that the decline in the use of hormonal methods, since 1988, was reversed by the beginning of 1990, with increasing reliance on the minipill. Data from our study on continuity of minipill use at three months indicated low continuity by initial "acceptors, ${ }^{13}$ a phenomenon that led to concern for the success of the postpartum program. It was felt that physicians found the minipill easy to give, and therefore were using it indiscriminately, forgoing the more difficult procedures of IUD insertion or tubal ligation. IMSS then decided to use the minipill as a postpartum option at six weeks postpartum for lactating women, rather than as an immediate postpartum option.

The early and unexpected policy effects of our research exemplify the way in which research results, even preliminary reports, can have unintended consequences. If there was a research bias, it was to prove the utility of introducing new postpartum methods to the IMSS system in terms of offering women wider choices in contraception. In fact, our research ultimately was affected by and affected the system it set out to study. The results we present here are not, therefore, invalid, but are of great interest in terms of how women make decisions regarding contraception and breastfeeding over the course of the postpartum period. The medical system's heavy influence on women's "choices" made it impossible to observe the free election by women of the method they want to use. The results are of interest because they refer to a real system, but they cannot offer data regarding a more ideal system. The situation is the opposite of one in which the researcher affects the system, and is instead a situation in which the research itself is affected by the system's bias.

\section{Methodology}

The study was designed to follow women for one year. Method choice was to be left to the mothers, and was to reflect normal IMSS procedures in the hospitals studied.

\footnotetext{
3 "Acceptors" refers to women who accepted the package of pills and said they intended to use them. These women were not given any other method. Of women who "initiated" use of the pill, continuity rates at three months were 71 percent (Querétaro) and 50 percent (Yucatán) among breastfeeding women, and 49 percent (Querétaro) and 50 percent (Yucatán) among non-breastfeeding women.
} 
Enrollment began simultaneously at both sites, in January 1991. Four hundred women at each site were enrolled in the minipill group, and four hundred women were enrolled at Querétaro for the IUD (the IUD is not offered in Yucatán). Women were initially interviewed in the hospital after giving birth, and subsequently at 3,6, and 12 months after the birth of their baby. The initial strategy was to conduct follow-up visits in the patients' regular IMSS clinics, or "medical units," but a large proportion of unkept appointments made home visits necessary.

\section{Results}

There were no differences among the groups on sociodemographic variables at enrollment by site or by contraceptive method used. Differences in place of follow-up visit were found, with more women followed up at home in Querétaro and at the clinic in Yucatán. No one refused follow-up interviews if contacted.

\section{Breastfeeding}

In all these groups of breastfeeding women, there is a steep fall in prevalence of breastfeeding between one and three months, reaching a level of about 60 percent. Another steep drop occurs between five and seven months, to a level of about 30 percent. The data show a consistent trend at both sites regarding medical advice and breastfeeding duration. If a woman receives advice regarding infant feeding while in the hospital, she is more inclined to still be breastfeeding at three and six months. If, however, she receives medical advice regarding feeding at the postnatal visit, she is less likely to continue breastfeeding. This trend reaches statistical significance for those women (Querétaro) using the IUD as their postpartum method. It appears that while advice regarding breastfeeding is positive in the immediate postpartum period, later advice (at the one-month postpartum visit) may advocate supplementation or other practices that contribute to the cessation of breastfeeding.

Women using the IUD breastfed for less time than did those using the minipill in either site. Among those who breastfed exclusively for from one to four months, the rates of any infant illness in the two weeks prior to the six-month visit were significantly lower than among those who never breastfed exclusively. The trend was the same for diarrheal disease.

The factor that appears to determine most strongly whether a woman continues to breastfeed at three months postpartum for all groups was work outside the home. Another important factor for all groups was whether the woman initiated breastfeeding in the hospital. At six months postpartum, a woman's decision to keep breastfeeding continued to be 
influenced by work outside the home in Yucatán, but in Querétaro it was influenced by schooling, followed by sex of the child (longer breastfeeding of sons). When breastfeeding and mother's work outside the home are examined across all groups at 3, 6, and 12 months postpartum, the negative relationship between the two variables is statistically significant at each point for each group. The implications of this finding for the IMSS system, which in theory provides day care for salaried working women near their place of work and allows breastfeeding breaks during the day, is significant.

\section{Contraception}

The 6- and 12-month follow-up interviews were more difficult to obtain than had been expected. The final outcomes were, for Querétaro, a response rate of 81 percent at three months, 52 percent at six months, and 70 percent at twelve months. For Yucatán, the figures were 83,64 , and 75 percent, respectively, and three, six, and twelve months. The possibility that the response rate is skewed is currently being investigated.

In Querétaro, 43 percent of the women who "accepted" pills never took them, while in Yucatán, 24 percent of those who accepted pills never took them. Therefore, the data on method choice are reported in two ways-those who "accepted" a method and those who "initiated use" of the method. This raises the question of whether women received methods they didn't want, or didn't understand how to use, or that were offered to them at the wrong time.

For women who initiated use of the methods, the continuation rates (life-table analysis) for minipill use in Querétaro are 47 percent at three months, 28 percent at six months, and 10.3 percent at twelve months. For those who abandoned the method, the net cumulative reported reason at each point was "change to another method," followed by headache, "other reasons," and "running out of pills." For women who initiated use of the minipill in Yucatán, the continuation rate at three months is 53 percent; at six months, 38 percent; and at twelve months, 22 percent. Cumulative reported reasons for stopping use in Yucatán are, first, "other not specified reasons," followed by bleeding, running out of pills, and changing method.

In Querétaro, the continuation rate for women who initiated IUD use was 71 percent at three months, 65 percent at six months, and 56 percent at twelve months. The most common reason for stopping method use was expulsion; followed by "other," inflammation of the "womb," and bleeding.

For those women who "accepted" (or in some cases were assigned) the minipill in 
Querétaro, at one year's time 52.9 percent of them were using some method of contraception: IUD, 20.7 percent; condoms and other "local" or traditional methods, 11 percent; minipill, 10.6 percent; combination orals, 5.7 percent; injectables, 2.7 percent; and tubal ligation, 2.2 percent. Of those who "accepted" the minipill in Yucatán, 63.7 percent were practicing some form of contraception at one year: minipill, 24.7 percent; combined orals, 27 percent; IUD, 4.6 percent; injectables, 3.7 percent; tubal ligation, 2.0 percent; and condoms and local methods, 1.7 percent. For "acceptors" of the IUD in Querétaro, 80.1 percent were practicing contraception at one year: IUD, 65.3 percent; orals, 8.3 percent; condoms, 3.6 percent; injectables, 1.8 percent; and tubal ligation, 1.1 percent.

\section{Conclusion}

In the IMSS system, the minipill is an important contraceptive choice for breastfeeding women in the postpartum period, capable of providing important contraceptive protection, particularly as a transitional method while women make decisions about method change, another pregnancy, or tubal ligation. What is critical is the quality and timing of information and counseling given to women, as well as assuring the easy resupply of the method in areas that are far away from the IMSS clinic and women who are not inclined to return after the first postpartum visit. 


\section{CHAPTER 6: \\ GOALS AND OPPORTUNITIES FOR POSTPARTUM PROGRAM DESIGN \\ Beverly Winikoff, Chair}

\section{Cost and Cost-Effectiveness Considerations \\ in Postpartum Family Planning Programs \\ based on a presentation by Ricardo Vernon)}

The goal of family planning programs is to help as many couples as possible achieve as much satisfaction as possible realize their reproductive intentions as closely as possiblethat is, the degree to which the number and timing of births fit the couple's intentions. Program effectiveness is thus, to some extent, a function of contraceptive acceptance by couples who want to plan births and of continued contraceptive use.

The first question we need to ask about postpartum programs is whether they are effective. In a study in Lima, Peru (Foreit, et al., 1993), when an immediate postpartum program was introduced on one floor of a hospital but not on another, at both 40-day and sixmonth follow-ups, prevalence was higher among women in the group to which the program had been available. At the six-month follow-up, over 80 percent of this experimental group used a method, compared with less than 70 percent of the control group, with the difference attributable to the IUDs inserted in the hospital. In this example, then, the postpartum program does appear to make a difference.

If programs are effective, a second question we can ask is whether they are costeffective, where one program is more cost-effective than another if it achieves the same amount of user satisfaction at less cost. Costs can be conceptualized as total costs, marginal costs, or opportunity costs. They include not only costs to the provider-related to facilities, labor, and materials—but also costs to the client-related, for example, to time, travel, and resupply. Despite their importance, these client-related costs often are not taken into account.

Various factors affect costs of postpartum services. The discussion that follows looks at several such factors, drawing on a literature that, unfortunately, is scant.

\section{Factors Affecting Costs}

Costs are affected by timing - by whether contraceptive provision occurs postplacentally, before hospital discharge, or later in the postpartum period. The Peruvian 
study cited above found the costs of an IUD insertion before discharge from the hospital to be far lower than the costs of an interval IUD insertion (US\$7.20 versus US $\$ 23.14$ ), as a result of the additional time required for the interval insertion. (Because of the norms of social security in Peru, the interval insertion was costed as two visits; but even if the cost is calculated as only one visit, the interval IUD still costs more than the postpartum IUD.)

A study in Nyeri, Kenya (Hubacher, et al., 1992) determined marginal provider costs of IUD insertions for the first year of protection. Insertions were divided into postplacental, before hospital discharge, and interval (six week) insertions. Differences in expulsion rates, which are highest for before-discharge insertions and lowest for interval insertions, were taken into account, since higher expulsion rates mean higher costs as a result of additional visits. The marginal provider costs were lowest for postplacental insertions (US\$3.37 per insertion), followed by before-discharge insertions (US\$3.97), and then interval insertions (US\$4.75).

Rate of return for postpartum visits and other follow-up visits also influences costeffectiveness. For example, program follow-up norms differ, so that one program might require that a woman return four times in the year following an IUD insertion, whereas another might require that she return only twice.

One method of contraception could prove more cost-effective than another if it leads to higher continuation rates. For example, data from 12 hospitals showed that 18 months after acceptance, continuation rates in terms both of the initial method adopted and any method were higher for initial IUD acceptors than for initial pill acceptors, and higher for initial pill acceptors than for initial acceptors of traditional methods.

Method costs themselves also differ. A study of postabortion provision of contraception in Hospital Obrero, in La Paz, Bolivia (Population Council, 1991) found that the cost of providing NORPLANT® was US $\$ 35.95$ per client, whereas the cost of providing an IUD was US $\$ 10.63$. Although costs in surgical time were similar, NORPLANT® was associated with far higher material and method costs. Of course, the longer the method is used, the more similar the costs per year of protection become.

The constellation of postpartum services of which a family planning program is part also influences program cost, or in any event influence the cost-benefit. The more services the client receives for a given cost, the greater the cost-benefit. Moreover, the addition of components to a program can increase the effectiveness of its original components. When a breastfeeding promotion program in Honduras was extended to include contraceptive promotion, not only did modern contraceptive prevalence increase, but breastfeeding 
increased, as well (de Chavez, et al., 1989).

Finally, there are labor costs-in particular, the different labor costs for different health workers (physicians, obstetric nurses, nurses, etc.). Such costs might themselves be affected by factors that can't be controlled. For example, in social security hospitals in Mexico, IUD insertions must be done by physicians, because they are not included in the job description for nurses negotiated with the union; as a result, labor costs for this method are increased.

\section{Conclusion}

The cost-effectiveness of a postpartum program is related to factors that can influence the satisfaction of users or the costs of a service. Many of these factors are under the control of managers. Under conditions of consumer indifference (i.e., where equal consumer satisfaction will result), and all other factors being equal, a program should try to provide the least expensive alternative, because in that way it will be able to serve a larger number of clients.

\section{Setting a Research Agenda}

based on a presentation by Anrudh Jain

This presentation does not specify a research agenda in postpartum programs.

Instead, it focuses upon a process that researchers can use to set a research agenda. Five key elements that need to be specified when setting a research agenda are the dependent variables, setting, intervention, issues, and design.

\section{Dependent Variables}

In postpartum research, three dependent variables of particular interest are (1) prevention of unwanted and unplanned births, (2) improved infant health, and (3) improved maternal health. Other dependent variables that Debbie Rogow mentioned in her presentation are women's sense of control and self-esteem. Next, irrespective of outcome variables selected for research, we need to make two decisions. First, how do we quantify outcomes? Second, what relative importance do we assign to different outcome variables? This second question must be addressed explicitly, since an intervention might have very different, even conflicting, effects on the three dependent variables. 


\section{Setting: Hospital versus Home Delivery}

A basic division in setting is between hospital and home as the place of delivery. This division indirectly addresses the effect of modernization, expansion of health services, and some of the differences between the situation in North America and developing countries. When we talk about postpartum programs, we are thinking about hospital deliveries, about the needs of women who have access to and use hospitals for delivery. Yet many women, especially in developing countries, do not have access to hospitals for delivery. In India, for example, 70 percent of deliveries occur at home. This group has been completely left out in our deliberations of the last two days. It is crucial that the needs of this second group of women be taken into account.

We know that levels of breastfeeding and fecundity postpartum, fertility, and infant mortality differ between the two settings. The hospital setting is associated with short breastfeeding - that is, high fecundity postpartum, low fertility, and low infant mortality; the home setting, conversely, is associated with long breastfeeding - that is, low fecundity postpartum, high fertility, and high infant mortality. We also know that in the hospital setting, different strategies in terms of timing of initiating contraception may have similar demographic outcomes as long as these strategies are equally accepted; in the home setting, by contrast, a mixed strategy (i.e., initiating contraception after resuming menstruation or at six months postpartum) seems superior to an immediate postpartum strategy as far as their impacts on the subsequent birth interval is concerned.

\section{Intervention}

Intervention, consisting of provision of accurate information and of services, must occur at some point in the recursive cycle from the gestation period to the postpartum period and to the interval period prior to the next gestation period. Essentially this is a three-part cycle: (1) a gestation period subdivided into trimesters; (2) a period in the hospital, subdivided into predelivery, delivery, and postdelivery segments; and (3) the subsequent postpartum and interval period, ended by a new pregnancy. With intervention, questions arise as to the content and timing of information and services and as to who decides about the timing of initiating contraception and the method appropriate for an individual client.

A key question related to the content is how to decide what is "accurate information." Among the group at this conference, the consensus about what comprises accurate information appears extensive, but there are also, undoubtedly, many disagreements. Other content questions concern the type of information to be provided and the type of methods to 
be made available.

In terms of timing, information can be provided at any point during the first and third parts of the cycle mentioned above. Provision of information in the hospital is less clear-cut, however. Information can be provided postdelivery; provision of information at delivery seems unacceptable. Whether information can be provided before delivery-whether women will retain information given at that point-is a question that remains to be answered. Services can be provided in the hospital postdelivery or at any subsequent point. The question is whether services can be provided at delivery. Under what circumstances is that ethical? Perhaps one can argue for provision of services at delivery for clients who had received information during the prenatal period and who have agreed to the procedure at the time of delivery. Otherwise, this timing seems to be unjustifiable.

Perhaps the most important question related to intervention is that of who makes the decisions. Is it feasible to leave choices of timing and method to clients? For such decisions to be informed, the relevant information must be put together in an understandable and unbiased way. Lack of bias is important, as providers sometimes become "salespeople" for the solutions they favor. How can this information be put together, and by whom?

\section{Research Issues}

We can single out the following two programmatic research issues: Is postpartum family planning better than a mixed or postamenorrheic strategy? Is a choice strategy better than either of the other alternatives? We know that, in terms of their effect on fertility, postpartum and mixed strategies, under short breastfeeding conditions characterized by hospital-based deliveries, are comparable if they are equally accepted. We do not, however, know which strategy is better in terms of effects on the other two dependent variables, infant and maternal health. Nor do we have answers on the effects of a choice strategy in comparison with the postpartum strategy.

Design can be considered in terms of the settings discussed above, hospital and home, with the hospital setting divided into hospitals that have a postpartum family planning program and hospitals that do not.

For hospitals with a postpartum program, we would first describe the current strategy, then attempt to design a better alternative strategy, based on choice of timing and method and on accurate information, and then compare the two strategies, their cost, and their effectiveness. Such comparisons should be in terms of the three dependent variables. For hospitals without a postpartum program, we can design an appropriate choice strategy and 
demonstrate its feasibility, cost, and effect. Should we, in addition, design an immediate postpartum strategy? I think not, if the main purpose is to compare it with the choice strategy.

For the home setting —and, as mentioned, this group is extremely important-the question is how to extend coverage to women who have no contact with hospitals for delivery. As the experience of the International Postpartum Program illustrated, designs that work for hospitals can prove unsuccessful when transferred to rural areas.

An important part of the answer might lie in the integration of services-integration at the level of the client, rather than at the more commonly discussed level of the provider or of the Ministry of Health. Dr. Diaz gave some good examples of mechanisms for achieving integration when she spoke of the clinic in Santiago, Chile, which uses community workers to identify and register all pregnant women in the neighborhood. If pregnant women are registered, we can then follow them to insure that they receive the entire range of information and services related to prenatal care, delivery, breastfeeding, contraceptive methods, immunization, and health check-ups-services that often are made available by different providers in a community but not integrated at the client level. Integration will depend ultimately on outreach workers, who will direct and track provision of information and services, and who, by working at the level of the individual, will ensure that clients' needs are met. 


\section{AFTERWORD: \\ Programmatic Issues at the Seminar on Rethinking Postpartum Health Care \\ based on a presentation by Debbie Rogow}

This discussion categorizes some key issues and questions that repeatedly emerged at the seminar, in order to better focus them and examine their implications for program design and implementation.

\section{Effects of Modernization on the Postpartum Period}

Modernization, which is inevitable, has brought changes in the ways we construct and understand the postpartum period, who controls it, and how disease and appropriate care are defined. It has brought changes in:

1. the structure and strength of support networks to the expectant and new mother, shifting the burden for providing physical and emotional support from traditional kinship networks to the conjugal unit;

2. concepts of time, with a shift from periodic to institutional time, which fits the needs of health-care providers and employers better than it does the needs of new mothers; and

3. epistemology, with empirical knowledge replacing spiritual knowledge as the dominant mode of knowing.

Traditional systems met a wide range of underlying needs of the postpartum period. They include the woman's needs for information, physical support, and emotional support and the infant's physical and emotional needs. For example, the need for physical support was met through prescribed periods of rest, nutritional prescriptions and proscriptions, and prescribed abstinence, which protected against infections and immediate conception.

The challenge for modern systems

It is increasingly necessary for modern systems to address the underlying needs of mothers and infants during the postpartum period. Unfortunately, extreme fragmentation in modern service systems has hindered an integrated approach to the postpartum period. Furthermore, the task has been complicated by new needs to be considered. For example, 
the shift toward a conjugal family structure has made fathers' needs more important, and the rise of sexually transmitted diseases (STDs) in many areas has resulted in a need when providing contraception to weigh concerns about pregnancy against concerns about infection.

The seminar participants reached a consensus on a number of "best practices." These included the following.

1. Providing information and education: Information gives women a sense of control and promotes healthy behavior. Programs that provide ongoing information about a range of reproductive health issues have had successful outcomes, including increases in breastfeeding frequency and duration, in contraceptive use, and in follow-up visit rates and improvements in infant outcomes. Contraceptive information should be provided as part of a general education package about reproductive health. Many women indicate they prefer to receive contraceptive information during the prenatal period, with follow-up in the postpartum period. Much information and education can be provided in group classes, which are less expensive than individual visits and may be more effective motivators. First-time mothers might be an appropriate priority target population, both because of their greater vulnerability and because of the potential for greatest long-term impact.

2. Providing emotional support: It was repeatedly noted that providing postpartum women with follow-up visits and "plain old attention" leads to positive outcomes for both mother and infant. Examples given ranged from a program in Brazil based on community-led support groups to a program in the United States for adolescent mothers. Support activities, like education activities, require staff training and allocation of adequate time for client-provider interaction if they are to be effective. One form of support might be to give women greater control over their reproductive and health decisions, a control modern medicine has greatly reduced. However, this potential goal remains controversial in perinatal and family planning programs.

3. Promoting healthy behaviors: Lacking support for ongoing tasks, many women have inadequate rest in the postpartum period. Problems such as postpartum depression might be related to physical exhaustion. To promote health, programs need to help mothers obtain support.

4. Integrating services: An integrated approach toward maternal health and infant health is needed. The package should include (1) prenatal clinical care, education, 
and counseling; (2) perinatal services; (3) breastfeeding programs; and (4) family planning.

\section{Questions about Postpartum Family Planning}

In contrast to a general consensus on appropriate practices for the other three service areas, there was some controversy about postpartum family planning —in particular, about which contraceptives are appropriate and when. There was agreement that some current practices might not be the best. Particular concerns were raised about the following service issues.

1. Immediate postpartum hormonal contraception: A number of participants expressed serious concern over the possibility that immediate postpartum hormonal contraception could lead to neuroendocrine changes in breastfed infants. It was suggested that women could be given oral contraceptives to begin when they stop fully breastfeeding or at six months postpartum.

2. Immediate IUD insertion: There was concern that if IUD insertion was not previously discussed, immediate insertion would entail abuses of informed consent. Also, because the perinatal period might be a time when the father has other sexual partners, immediate insertion might take place when the woman is particularly vulnerable to infection. It was suggested that for women using the lactational amenorrhea method (LAM), IUD insertion could be delayed.

3. Failure to adequately provide or explain LAM, barrier methods, and withdrawal: These methods, which can be useful at least for a short-term period, are often inadequately provided or explained, or not discussed at all. There was disagreement over whether women would then switch to more effective methods.

4. Appropriateness of postpartum sterilization: There was support for the idea that postpartum sterilization is appropriate as long as the choice is discussed during the pregnancy, preferably during the second trimester.

\section{Questions for Study}

Participants raised a number of questions that must be addressed if providers are to organize services that respond to the clients' needs. These questions include:

* If women who plan to use LAM are given a pill package or condoms when they 
leave the hospital, will they remember to use the method-and how to use itsix months later?

* If offered information, support, and needed services, will women return for follow-up visits?

* How do patterns of sexuality change during the perinatal and postpartum periods? Which methods of contraception are most compatible with people's sexual lives?

* How are the postpartum needs of the growing number of unpartnered mothers being met in the absence of both traditional and modern support systems?

* What interventions most effectively foster father involvement? What physical and mental health outcomes does such involvement have for the father, the mother, and the child?

* Where sterilization is popular, would women seek prenatal care earlier if it is required for postpartum sterilization?

* How do mother-infant bonding practices differ by gender of offspring? How do these differences affect child health outcomes?

Lively discussion followed each of the panels. Overall, the group was in agreement on a large number of issues, while others remain somewhat controversial. 


\section{Bibliography}

American Health Consultants. 1993. "Are NORPLANT®, Depo-Provera good options for nursing mothers?" Contraceptive Technology Update 14, 3:46-8.

Arnold, F. and A.K. Blanc. 1990. Demographic and Health Surveys Comparative Studies 2: Fertility Levels and Trends. Columbia, Md.: Institute for Resource Development.

Bhatia, S. and Y. Kim. 1984. "Oral contraception in Bangladesh." Studies in Family Planning 15, 5:233-41.

Boulier, B.L. 1977. "Children and household economic activity in Laguna, Philippines." Journal of Philippine Development 4, 2: 195-222.

Bracher, M. 1992. "Breastfeeding, lactational infecundity, contraception and the spacing of births: implications of the Bellagio Consensus Statement." Health Transition Review 2, 1: 19-47.

Bracken, M.B., et al. 1990. "Meta-analysis of the Risk of Birth Defects with Oral Contraceptives." Obstetrics and Gynecology 76:552-57.

Campbell, S.B. and J.F. Cohn. 1991. "Prevalence and correlates of postpartum depression in first-time mothers." Journal of Abnormal Psychology 100, 4:594-99.

Canto, T.E., L. Vera, L.E. Polanco, and C.E. Colven. 1989. "Mini-pill in lactating women." Contraception 39, 6:589-601.

Centro de Estudios de Población y Paternidad Responsable (CEPAR), Instituto Nacional de Investigaciones Nutricionales y Medico Sociales (INMUS), Institute for Resource Development/Westinghouse (IRD). 1988. Ecuador: Encuesta Demografica y de Salud Familiar 1987 Quito: CEPAR, INMUS, IRD.

Chi, I.C., M. Potts, L.R. Wilkens, and C.B. Champion. 1989. "Performance of Copper T380A intrauterine device in breastfeeding women." Contraception 39:603-618.

Coeytaux, F. 1989. "Celebrating mother and child on the fortieth day: The Sfax, Tunisia postpartum program." Quality/Calidad/Qualité No. 1. New York: The Population Council.

D'Addato, F., C. Andreoli, F. Andreoli, G.P. Basunti, and A. Repinto. 1991. "Neuroendocrine factors in postpartum blues." Minerva Psichiatric 32, 2:83-87. 
de Chávez, A., A. de Romero, V. Ortiz, J. Zelaya, J. Canahuati, and J.W. Townsend. 1989. "The promotion of breastfeeding and family planning." Final technical report, Proyecto de Apoyo a la Lactancia Materna (PROALMA), Instituto Hondureño de Seguridad Social (IHSS) and The Population Council. Tegulcigalpa, D.C., Honduras.

Diaz, S., P. Miranda, A. Brandeis, H. Cardenas, and H.B. Croxatto. 1991. "Mechanism of Actionof Progesterone as Contraceptive for Lactating Women." Annals of the New York Academy of Science 626:11-21.

Diaz, S., C. Herreros, G. Juez, et al. 1985. "Fertility regulation in nursing women: VII. Influence of Norplant® levonogestrel implants upon lactation and infant growth." Contraception 32, 1:53-74.

Dunson, T.R., V.L. McLaurin, G.S. Grubb, and A.W. Rosman. 1993. "A multicenter trial of a progestin-only oral contraceptive in lactating women." Contraception 47:23-35.

Enkin, M., M.J.N.C. Keirse, and I. Chalmers. 1989. A Guide to Effective Care in Pregnancy and Childbirth. Oxford: Oxford University Press.

Fleming, A.S., E. Klein, and C. Corter. 1992. "The effects of a social support group on depression, maternal attitudes and behavior in new mothers." Journal of Child Psychology and Psychiatry 33, 4:685-98.

Foreit, K., J. Foreit, G. Lagos, and A. Guzmán. 1993. "Effectiveness and cost-effectiveness of postpartum contraception in Lima." International Family Planning Perspectives 19, 1:19-24.

Fullerton, J.T. and R. Severino. 1992. "In-Hospital Care for Low-Risk Childbirth-Comparison with Results from the National Birth Center Study," Journal of Nurse-Midwifery 37, 5:331-340.

González-Cossío, T., J-P. Habicht, H. Delgado, and K.M. Rasmussen. 1991. "Food supplementation during lactation increases infant milk intake and the proportion of exclusive breastfeeding." Federation of American Societies for Experimental Biology (FASEB) Journal 5:A917.

Guillebaud, J. 1991. "Contraception after pregnancy." British Journal of Family Planning 16, 4:16-29.

Hannah, P., D. Adams, V. Glover, and M. Sandler. 1992. "Abnormal platelet 5hydroxytryptamine uptake and imipramine binding in postnatal dysphoria." Journal of Psychiatric Research 26, 1:69-75. 
Harlap, S. 1987. "Exposure to contraceptive hormones through breast milk-are there longterm health and behavioral consequences?" International Journal of Gynaecology and Obstetrics 25, Supplement:47-55.

Harkness, S. 1987. "The cultural mediation of postpartum depression." Medical Anthropological Quarterly 1:194-209.

Hellman, L. and J. Pritchard. 1971. Williams Obstetrics, 14th edition. New York: Meredith Corporation.

Hubacher, D., B. Janowitz, E.M. Mate, and C. Waszak. 1992. "Comparing the costs of two IUD programs in a Kenyan hospital." Paper presented at the annual meeting of the APHA. (All data are preliminary and should not be quoted.)

Jaffe, B., et al. 1988. "Long-term effects of MPA on human progeny: Intellectual Development." Contraception 37, 6:607-19.

Kennedy, K.I. and C.M. Visness. 1992. "Contraceptive efficacy of lactational amenorrhea." Lancet 339:227-30.

Kennedy, K.I. 1991. "Breastfeeding and the double protection dilemma." Family Health International, Postpartum conference, Article II, September.

Kennedy, K., R. Rivera, A. McNeilly, et al. 1989. "Consensus Statement on the use of Breastfeeding as a Family Planning Method." Contraception 39:477-96.

Knodel, J. and N. Chayovan. 1989. "Contraceptive initiation patterns in Thailand." Health and Population Studies Based on the 1987 Thailand Demographic and Health Survey. Bangkok: Institute of Population Studies, Chulalongkorn University.

Kurz, K.M., J-P. Habicht, K.M. Rasmussen, and S.J. Schwager. 1993. "Effects of maternal nutritional status and maternal energy supplementation on length of postpartum amenorrhea among Guatemalan women." American Journal of Clinical Nutrition, in press.

Lanczik, M., H. Spingler, A. Heidrich, T. Becker, B. Kretzer, P. Albert, and J. Fritze. 1992. "Postpartum blues: depressive disease or pseudoneurasthenic syndrome." Journal of Affective Disorders 25, 1:47-52.

Laukaran, V.H. and Beverly Winikoff. 1985. "Contraceptive use, amenorrhea, and breastfeeding in postpartum women." Studies in Family Planning 16, 6:293-01. 
Lesetedi, L., G. Mompati, and P. Khulumani, et al. 1989. Botswana Family Health Survey, 1988. Gaberone, Botswana: Central Statistical Office, Ministry of Finance and Development Planning; Family Health Division, Ministry of Health; and Columbia, Md.: Institute for Resource Development/Macro Systems, Inc.

Lloyd, C.B. 1993. "Family and gender issues for population policy." Population Council Research Division Working Paper No. 48.

McCann, M.F., A.V. Moggia, J.E. Higgins, M. Potts, and C. Becker. 1989. "The effects of a progestin-only oral contraceptive (levonorgestrel $0.03 \mathrm{mg}$ ) on breast-feeding." Contraception 40, 6:635-648.

McGuire, M.K., W.R. Butler, and K.M. Rasmussen. 1992. "Chronic food restriction amplifies the effect of lactation on the duration of postpartum anestrus in rats." Journal of Nutrition 122:1726-30.

O'Hara, M.W., J.A. Schlecte, D.A. Lewis, and E.J. Wright. 1991. "Prospective study of postpartum blues. Biologic and psychosocial factors." Archives of General Psychiatry 48, 9:801-06.

Pardthaisong, T. and R.H. Gray. 1991. "In utero exposure to steroid contraceptives and outcome of pregnancy." American Journal of Epidemiology 134, 8:795-803.

Pérez, A., M. Labbok, and J. Queenan. 1992. "A Clinical Study of the Lactational Amenorrhea Method for Family Planning." Lancet 339:968-70.

Population Council. 1991. Fourth Semi-Annual Report. INOPAL II. Mexico City and New York: Population Council.

Rasmussen, K.M. and K.L. Fischbeck. 1987. "Effect of repeated reproductive cycles on pregnancy outcome in ad libitum-fed and chronically food-restricted rats." Journal of Nutrition 117:1959-66.

Rooks, J.P., N.L. Weatherby, E.K.M. Ernst, S. Stapleton, D. Rosen, and A. Rosenfield. 1989. "Outcomes of care in birth centers: the National Birth Center Study." New England Journal of Medicine 321, 26:1804-11.

Rooks, J.P., N.L. Weatherby, and E.K.M. Ernst. 1992a. "The National Birth Center Study-Part I-Methodology and Prenatal Care and Referrals." Journal of Nurse-Midwifery 37, 4:222-53.

—. 1992b. "The National Birth Center Study-Part II-Intrapartum and Immediate Postpartum and Neonatal Care." Journal of Nurse-Midwifery 37, 5:301-30. 
—. 1992c. "The National Birth Center Study-Part III-Intrapartum and Immediate Postpartum and Neonatal Complications and Transfers, Postpartum and Neonatal Care, Outcomes, and Client Satisfaction," Journal of Nurse-Midwifery 37, 6:361-97.

Rosenberg, M.J., A.J. Davidson, J.-H. Chen, F.N. Judson, and J.M. Douglas. 1992. "Barrier Contraceptives and Sexually Transmitted Diseases in Women: A Comparison of Female-Dependent Methods and Condoms." American Journal of Public Health 82, 5:669-75.

Schön, D.A. 1983. The Reflective Practitioner: How Professionals Think in Action. New York: Basic Books.

Sivin, I., et al. 1992. "Rates and outcomes of planned pregnancy after use of Norplant $\AA$ capsules, Norplant $\AA^{\text {II }}$ rods, or levonorgestrel-releasing or copper TCu $380 \mathrm{Ag}$ intrauterine contraceptive devices." American Journal of Obstetrics and Gynecology 166, 4:1208-1213.

Stern, G. and L. Kruckman. 1983. "Multi-disciplinary perspectives on post-partum depression: An anthropological critique." Social Science and Medicine 17:1027-41.

Wade, K.E., F. Sevilla, and M.H. Labbok. 1992. "LAM acceptability among family planning clients: Process analysis and interim results of a pilot study." Unpublished manuscript.

WHO Task Force on Oral Contraceptives. 1988. "Effects of hormonal contraceptives on breastmilk composition and infant growth." Studies in Family Planning 19, 6:361-369.

. 1987. "Contraception during the postpartum period and during lactation: The effects on women's health." International Journal of Gynaecology and Obstetrics 25 Suppl:13-26.

. 1984. "Effects of hormonal contraceptives on milk volume and infant growth." Contraception 30, 6:505-521.

Williamson, N.E., S. Thapa, and S. Balogh. 1991. "Introducing New Methods, Popularizing Available Methods, and Encouraging Correct Use and Continuation." In Operations Research: Helping Family Planning Programs Work Better. New York: Wiley-Liss, Inc. 233-257.

Winikoff, B. and B. Mensch. 1991. "Rethinking Postpartum Family Planning." Studies in Family Planning 22, 5:294-307.

Winkvist, A. 1992. "Maternal depletion among Pakistani and Guatemalan women." Ph.D. dissertation. Ithaca, NY: Cornell University. 


\section{RETHINKING POSTPARTUM HEALTH CARE}

December 10-11, 1992

The Population Council

New York, NY

\section{Participant List}

Dr. Claude Aguillaume

Population Council

Center for Biomedical Research

Tower Building

1230 York Avenue

New York, NY 10021

(212) 327-8731

Ms. Karen Andes

Northwestern University

1347 W. Estes, Apt. E-1

Chicago, IL 60626

Dr. Marcia Angle

INTRAH

UNC School of Medicine

208 N. Columbia St.

Chapel Hill, NC 27514

(919) 966-5636

Fax: 919-966-6816

Ms. Claudette Bailey

SEATS Project

John Snow, Inc.

1616 N. Fort Myer Drive, 11th floor

Arlington, VA 22209

(703) 528-7474

Mr. San Balogh

Family Health International

Research Triangle Park Branch

One Triangle Drive

P.O. Box 13950

Durham, NC 27709

(919) 544-7040

Fax: 919-544-7261
Ms. Karen Beattie

The Population Council

One Dag Hammarskjold Plaza

New York, NY 10017

(212) 339-0618

Fax: 212-755-6052

Ms. Martha Brady

The Population Council

One Dag Hammarskjold Plaza

New York, NY 10017

(212) 339-0618

Fax: 212-755-6052

Dr. Vilneide Braga Serva

Instituto Materno Infantil de

Pernambuco (IMIP)

Rua dos Coelhos, 300 - Boa Vista

Recife, Pernambuco, Brazil

Dr. George Brown

The Population Council

One Dag Hammarskjold Plaza

New York, NY 10017

(212) 339-0600

Fax: 212-755-6052

Ms. Judith Bruce

The Population Council

One Dag Hammarskjold Plaza

New York, NY 10017

(212) 339-0641

Fax: 212-755-6052 
Dr. Aysen Bulut

Institute of Child Health

Tip Fakultesi

Chapa, Istanbul, Turkey

011-90-1-525-58816 (or 53614)

Fax: 011-90-1-631-3997

Mr. Stewart Burden

John D. and Catherine T. MacArthur

Foundation

140 S. Dearborn Street, Suite 1100

Chicago, IL 60603-5285

(312) $726-8000$

Ms. Laurie Cappa

SEATS Project

John Snow, Inc.

1616 N. Fort Myer Drive, 11th floor

Arlington, VA 22209

(703) 528-7474

Dr. Mary Ann Castle

Consultant

290 West 236th Street

New York, NY 10463

(212) 601-0007

Mme. Souad Chater

Consultant

Rue 7183, No. 2 El Manar 1

Tunis 1004, Tunisia

011-216-1-88-0181 (H)

Fax: 011-216-1-794-117

Dr. Davy Chikamata

The Population Council

P.O. Box 17643

Nairobi, Kenya

011-254-2-447871

Fax: 011-254-2-449074
Dr. Colette Dehlot

The Population Council

P.O. Box 17643

Nairobi, Kenya

011-254-2-447871

Fax: 011-254-2-449074

Dr. Juan Diaz

The Population Council

Caixa Postal 6181

13081 Campinas

Sao Paulo, Brazil

011-55-192-393004

Fax: 011-55-192-392440

Dr. Soledad Diaz

Instituto Chileno de Medicina Reproductiva (ICMER)

José Ramón Gutiérrez 295 - Depto. 3

Correo 22, Casilla 96

Santiago, Chile

011-562-6321988

Fax: 011-562-6336204

Dr. Christopher Elias

The Population Council

One Dag Hammarskjold Plaza

New York, NY 10017

(212) 339-0627

Fax: 212-755-6052

Ms. Andrea Eschen

The Population Council

One Dag Hammarskjold Plaza

New York, NY 10017

(212) 339-0638

Fax: 212-755-6052

Ms. Randee Falk

25 Plaza Street, Apt. 5M

Brooklyn, NY 11217

(718) 857-0803 
Professor Mahamadou Fall

Faculte de Medecine et de Pharmacie

Dakar, Senegal

011-221-25-07-78

Fax: 011-221-25-80-05

Dr. Mahmoud Fathalla

The Rockefeller Foundation

1133 Avenue of the Americas

New York, NY 10036

(212) 869-8500

Fax: 212-764-3468

Dr. Anibal Faundes

The Population Council

Caixa Postal 6181

13081 Campinas

Sao Paulo, Brazil

011-55-192-393004

Fax: 011-55-192-392440

Ms. Barbara Feringa

U.S. Agency for International Development (USAID)

Research Division

Office of Population

S\&T/POP, SA-18

Washington, DC 20523-1819

(703) 243-8666 (x27)

Fax: 703-358-9271

Dr. John Gill

The Population Council

P.O. Box 11-1213

Nana Post Office

Bangkok 10112, Thailand

011-66-2-251-4766

Fax: 011-66-2-255-5513
Ms. Joanne Gleason

The Population Council

One Dag Hammarskjold Plaza

New York, NY 10017

(212) 339-0603

Fax: 212-755-6052

Dr. Ellen Hardy

CEMICAMP

Rua Luverci Pereira de Souza, 1661

Cidade Universitária

CEP 13081

Campinas, Sao Paulo, Brazil

011-01-92-393004

Ms. Nancy Harris

SEATS Project

John Snow, Inc.

1616 N. Fort Myer Drive, 11th floor

Arlington, VA 22209

(703) 528-7474

Ms. Margaret Hempel

The Ford Foundation

320 East 43 Street

New York, NY 10017

(212) $573-5000$

Ms. Jane Hughes

Associate Director

Population Sciences

The Rockefeller Foundation

Population Sciences Division

1133 Avenue of the Americas

New York, NY 10036

(212) $869-8500$

Fax: 212-764-3468

Ms. Andrea Irvin

International Women's Health Coalition

24 East 21st Street, 5th Floor

New York, NY 10010

(212) 979-8500 
Dr. Anrudh Jain

The Population Council

One Dag Hammarskjold Plaza

New York, NY 10017

(212) 339-0639

Fax: 212-755-6052

Dr. Kathy Kennedy

Family Health International

One Triangle Drive, PO Box 13950

Research Triangle Park Branch

Durham, N.C. 27709

(919) 544-7524

Fax: 919-544-7261

Dr. Barbara Kwast

MotherCare

John Snow, Inc.

1616 N. Fort Meyer Dr.

Arlington, VA 22209

(703) 528-7474

Dr. Virginia Laukaran

Georgetown University

School of Medicine

Department of OB/GYN

3800 Reservoir Road, NW

Washington, DC 20007-2197

(202) 687-1392

Ms. Rebecka Lundgren

The Population Council

Residencia Casavola No. 37

Area Bancaplan, Miraflores

Tegucigalpa, Honduras

011-504-32-60-21

Fax: 011-504-32-60-21

Dr. Barbara Mensch

The Population Council

One Dag Hammarskjold Plaza

New York, NY 10017

(212) 339-0640

Fax: 212-755-6052
Ms. Diana Measham

Family Care International

588 Broadway, Ste. 510

New York, NY 10012

(212) $941-5300$

Fax: 212-941-5563

Ms. Janet Molzan

Doctoral Student

Johns Hopkins University

Department of Population Dynamics

2915 Guilford Avenue

Baltimore, MD 21218

(410) 366-6114

Dr. Axel Mundigo

World Health Organization

Special Programme of Research, Development and Research Training in Human Reproduction

1211 Geneva 27, Switzerland

011-41-22-791-3370

Ms. Donna Nager

The Population Council

One Dag Hammarskjold Plaza

New York, NY 10017

(212) 339-0602

Fax: 212-755-6052

Dr. Penda N'Diaye

The Population Council

B.P. 21027

Dakar, Senegal

011-221-24-19-93

Fax: 011-221-24-19-98

Lucile F. Newman, Ph.D.

Professor

Department of Community Health

Brown University

Providence, RI 02912

(401) 863-2412 
Ms. Chloe O'Gara

Wellstart

$3333 \mathrm{~K}$ Street, NW

Washington, DC 20007

(202) 298-7979

Dr. Amy Pollack

Association for Voluntary

Surgical Contraception (AVSC)

79 Madison Avenue

New York, NY 10016

(212) $561-8000$

Dr. Aurora Rabago

Academia Mexicana de Investigation

de Demografica Medica (AMIDEM)

Bajio 203, 1er. Piso

Mexico City D.F., Mexico

011-52-5-280-1725

Fax: 011-52-5-281-0702

Ms. Ann Robbins

The Population Council

Center for Biomedical Research

1230 York Avenue

New York, NY 10021

(212) 327-8728

Fax: 212-327-7678

Ms. Debbie Rogow

Consultant

709 W. Mt. Airy Avenue

Philadelphia, PA 19119

(215) 242-3383

Ms. Gabrielle Ross

International Women's Health Coalition

24 East 21st Street, 5th Floor

New York, NY 10010

(212) $979-8500$
Ms. Patricia Semeraro

Consultant

11 Oak Drive

New Hyde Park, NY 11040

(516) 354-0198

Dr. Michele G. Shedlin

Sociomedical Resource Associates, Inc.

181 Post Road West

Westport, CT 06880

(203) 454-0505

Dr. Jim Shelton

U.S. Agency for International Development (USAID), Training Division

Rm. 806D, ST/POP/IT, SA - 18

Washington, DC 20523

Dr. Nancy Sloan

The Population Council

One Dag Hammarskjold Plaza

New York, NY 10017

(212) 339-0601

Fax: 212-755-6052

Ms. Cynthia Steele Verme

Association for Voluntary

Surgical Contraception (AVSC)

79 Madison Avenue

New York, NY 10016-7802

212-561-8009

Dr. John Stoeckel

The Population Council

P.O. Box 11-1213

Nana Post Office

Bangkok 10112, Thailand

011-66-2-251-4766

Fax: 011-66-2-255-5513 
Mr. Kim Streatfield

The Population Council

P.O. Box 6016

Gulshan, Dhaka, Bangladesh

011-880-2-883127

Fax: 011-880-2-883132

Dr. Kathryn Tolbert

The Population Council

Apartado Postal 105-152

11560 Mexico, D.F. Mexico

011-905-203-8288

Fax: 011-905-254-4630

Ms. Sally Tom

West Virginia University

School of Nursing

Health Sciences Center

Charleston Division

3110 MacCorkle Avenue, S.E.

Charleston, WV 25304

(304) 347-1253

Dr. Nahid Toubia

The Population Council

One Dag Hammarskjold Plaza

New York, NY 10017

(212) 339-0632

Fax: 212-755-6052

Dr. Penny Van Esterik

Department of Anthropology

York University

Vari Hall, 4700 Keele Street

Toronto, Ontario M3J 1P3, Canada

(416) 736-5261

Fax: 416-736-5768

Ms. Gilberte Vansintejan

Association for Voluntary Surgical

Contraception (AVSC)

79 Madison Avenue

New York, NY 10016

(212) 561-8009
Dr. Ricardo Vernon

The Population Council

Apartado Postal 105-152

11560 Mexico, D.F. Mexico

011-905-203-8288

Fax: 011-905-254-4630

Ms. Mary Beth Weinberger

United Nations Population Division

Fertility and Family Planning

Studies Section

1 UN Plaza

New York, NY 10017

(212) 963-4531

Dr. Beverly Winikoff

The Population Council

One Dag Hammarskjold Plaza

New York, NY 10017

(212) 339-0623

Fax: 212-755-6052

Dr. Celia Woodfill

U.S. Agency for International Development (USAID)

Research Division

Office of Population

Rm. 820, RD/POP/R, SA-18

Washington, DC 20523-1819

(703) 875-5049

Dr. Huda Zurayk

The Population Council

P.O. Box 115

Dokki, Cairo, Egypt

011-202-570-1733

Fax: 011-202-570-1804 